\title{
In Vitro Modeling of the Bipolar Disorder and Schizophrenia Using Patient-Derived Induced Pluripotent Stem Cells with Copy Number Variations of $P C D H 15$ and RELN
}

\begin{abstract}
(1)Takaya Ishii, ${ }^{1,2}$ Mitsuru Ishikawa, ${ }^{1}$ Koki Fujimori, ${ }^{1}$ Takuji Maeda, ${ }^{1,3}$ Itaru Kushima, ${ }^{3,4,5}$ Yuko Arioka, ${ }^{3,4}$ [D Daisuke Mori, ${ }^{3}$ Yuhki Nakatake, ${ }^{6}$ Bun Yamagata, ${ }^{7}$ Shintaro Nio, ${ }^{7}$ (1) Takahiro A. Kato, ${ }^{8}$ Nan Yang, ${ }^{9,10}$ Marius Wernig, ${ }^{9}$ Shigenobu Kanba, ${ }^{8}$ - Masaru Mimura, ${ }^{7}$ Norio Ozaki, ${ }^{3}$ and ${ }^{\circledR}$ Hideyuki Okano ${ }^{1}$
\end{abstract}

https://doi.org/10.1523/ENEURO.0403-18.2019

${ }^{1}$ Department of Physiology, Keio University School of Medicine, Shinjuku-ku, Tokyo 160-8582, Japan, ${ }^{2}$ iPS CellBased Drug Discovery, Drug Research Division, Sumitomo Dainippon Pharma. Co., Ltd, Osaka, Osaka 554-0022, Japan, ${ }^{3}$ Department of Psychiatry, Nagoya University Graduate School of Medicine, Aichi, Nagoya 466-8550, Japan, ${ }^{4}$ Institute for Advanced Research, Nagoya University, Aichi, Nagoya 466-8550, Japan, ${ }^{5}$ Medical Genomics Center, Nagoya University Hospital, Aichi, Nagoya 466-8550, Japan, ${ }^{6}$ Department of Systems Medicine, Keio University School of Medicine, Shinjuku-ku, Tokyo 160-8582, Japan, ${ }^{7}$ Department of Neuropsychiatry, Keio University School of Medicine, Shinjuku-ku, Tokyo 160-8582, Japan, ${ }^{8}$ Department of Neuropsychiatry, Graduate School of Medical Sciences, Kyushu University, Fukuoka, Fukuoka 812-8582, Japan, ${ }^{9}$ Institute for Stem Cell Biology and Regenerative Medicine and Department of Pathology, Stanford University School of Medicine, Stanford, California 94305, and ${ }^{10}$ Department of Neuroscience, Friedman Brian Institute, Black Family Stem Cell Institute, Icahn School of Medicine at Mount Sinai, New York 10029

\section{Visual Abstract}
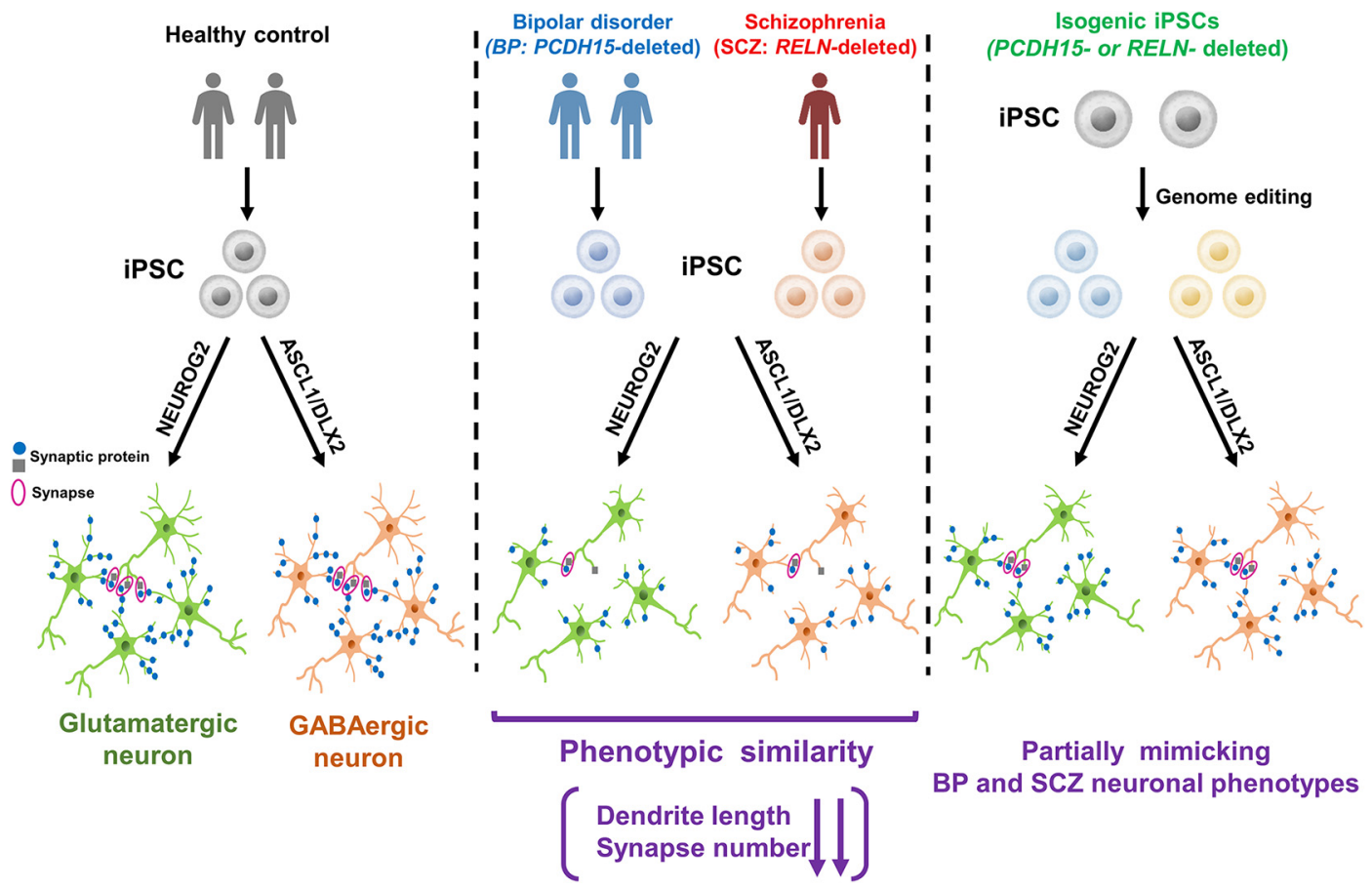


\section{Significance Statement}

Useful in vitro models of psychiatric disorders such as schizophrenia and bipolar disorder are urgently required for pathological analysis and drug discovery. In this study, mature excitatory and inhibitory neurons were induced from patient-derived induced pluripotent stem cells. The patient-derived induced neurons exhibited abnormalities in dendrite and synapse formation in vitro, which are similar to the previously reported findings observed in postmortem brains. Our in vitro model may reflect general phenotypes of psychiatric disorders and can be used to further examine therapeutic targets.

Bipolar disorder (BP) and schizophrenia (SCZ) are major psychiatric disorders, but the molecular mechanisms underlying the complicated pathologies of these disorders remain unclear. It is difficult to establish adequate in vitro models for pathological analysis because of the heterogeneity of these disorders. In the present study, to recapitulate the pathologies of these disorders in vitro, we established in vitro models by differentiating mature neurons from human induced pluripotent stem cells (hiPSCs) derived from BP and SCZ patient with contributive copy number variations, as follows: two BP patients with PCDH15 deletion and one SCZ patient with RELN deletion. Glutamatergic neurons and GABAergic neurons were induced from hiPSCs under optimized conditions. Both types of induced neurons from both hiPSCs exhibited similar phenotypes of MAP2 (microtubule-associated protein 2)-positive dendrite shortening and decreasing synapse numbers. Additionally, we analyzed isogenic $P C D H 15-$ or RELN-deleted cells. The dendrite and synapse phenotypes of isogenic neurons were partially similar to those of patient-derived neurons. These results suggest that the observed phenotypes are general phenotypes of psychiatric disorders, and our in vitro models using hiPSC-based technology may be suitable for analysis of the pathologies of psychiatric disorders.

Key words: bipolar disorder; copy number variations; GABAergic neurons; glutamatergic neurons; induced pluripotent stem cells; schizophrenia

\section{Introduction}

Both bipolar disorder (BP) and schizophrenia (SCZ) are chronic and debilitating psychiatric disorders that affect $\sim 1 \%$ of the worldwide population (McGrath et al., 2008;

Received October 17, 2018; accepted September 3, 2019; First published September 20, 2019.

H.O. is a founding scientist of SanBio Co. Ltd. and K Pharma Inc. T.I. and K.F are employed by Sumitomo Dainippon Pharma Co., Ltd. H.O. and N.O. received research funding from Sumitomo Dainippon Pharma Co., Ltd. The authors declare no other competing financial interests.

Author contributions: T.I., M.I., D.M., S.K., M.M., N.O., and H.O. designed research; T.I., M.I., K.F., T.M., I.K., and Y.A. performed research; T.I. and K.F. analyzed data; T.I., K.F., I.K., T.A.K., and H.O. wrote the paper; Y.N., B.Y., S.N., T.A.K., N.Y., and M.W. contributed unpublished reagents/analytic tools.

The work was supported by the Japan Agency for Medical Research and Development under Grants JP16bk0104016, JP18dm0107087, JP18dm0207005, JP19dm0207075h0001, JP18dk0307081, JP18dm0107095, JP19bm0804003h0003, JP19bm0804014h0103, and JP17dk0307047; and Japan Society for the Promotion of Science KAKENHI Grants JP1710083, JP26830018, JP18H04042, and JP16H02666.

Acknowledgments: We thank the Collaborative Research Resources, School of Medicine, Keio University for technical assistance with microarray analysis. We also thank Dr. Minoru S.H. Ko (Keio University) and Dr. K. Yusa (Sanger Institute) for the provision of plasmids; Dr. T. Sone (Keio University) for the preparation of plasmids; Dr. N. Kuzumaki (Hoshi University) for assistance in experimental design and supervision of the study; and A. Ohnishi (Hoshi University) for technical assistance in the generation of iPSCs.

Correspondence should be addressed to Hideyuki Okano at hidokano@a2.keo.jp.

https://doi.org/10.1523/ENEURO.0403-18.2019

Copyright (C) 2019 Ishii et al.

This is an open-access article distributed under the terms of the Creative Commons Attribution 4.0 International license, which permits unrestricted use, distribution and reproduction in any medium provided that the original work is properly attributed.
Grande et al., 2016). Although these disorders are highly heritable (Craddock and Sklar, 2013; Millan et al., 2016), the molecular mechanisms underlying the complex pathology of these disorders remain to be elucidated.

There are limitations to the recapitulation of clinical characteristics in animal models and postmortem brain studies because of genetic heterogeneity ( $O$ 'Shea and Mclnnis, 2016; Prytkova and Brennand, 2017). Therefore, reliable models that functionally mimic live human brains are sought after. Induced pluripotent stem cells (iPSCs) are expected to become a promising tool for recapitulating disease-specific phenotypes in vitro (Okano and Yamanaka, 2014; O'Shea and McInnis, 2016; Watmuff et al., 2016; Prytkova and Brennand, 2017; Tobe et al., 2017). Although recent studies established iPSCs from BP and SCZ patients and induced neurons to analyze phenotypes (O'Shea and Mclnnis, 2016; Prytkova and Brennand, 2017; Wen, 2017), the maturity and subtype specificity of induced neurons remain to be considered. Thus, analysis of mature and subtype-specific neurons is required for further elucidation of the pathologies. It has been suggested that the collapse of the excitation-inhibition (E/I) balance plays key roles in BP and SCZ (Gao and Penzes, 2015; Lee et al., 2018). Therefore, it is important to focus on certain neurons that are the main players in the $E / I$ balance, such as glutamatergic neurons and GABAergic neurons. Recent studies have shown that transcription factor overexpression enabled iPSCs to be differentiated into specific neurons, including glutamatergic neurons (Zhang et al., 2013) and GABAergic neurons (Colasante et al., 2015; Yang et al., 2017). 
Many genetic mutations are associated with these disorders, especially copy number variations (CNVs), which are important contributive factors that affect the onset and treatment resistance of BP and SCZ (Georgieva et al., 2014; Green et al., 2016; Kushima et al., 2017). Thus, to analyze the pathologies, we used iPSC lines derived from patients who carried certain CNVs: two BP patients with $P C D H 15$ exonic deletions and an SCZ patient who carried an RELN exonic deletion. Protocadherin 15 (PCDH15), encoded by $P C D H 15$, is a member of the cadherin superfamily. $\mathrm{PCDH} 15$ mutations cause Usher syndrome, which results in hearing vision loss (Ahmed et al., 2001; Alagramam et al., 2001; Kim et al., 2011). A recent genome-wide association study suggested that $P C D H 15$ is associated with psychiatric disorders (Lo et al., 2017). In addition, de novo or rare exonic deletions in $\mathrm{PCDH} 15$ were identified in BP patients (Georgieva et al., 2014; Noor et al., 2014). These studies suggested that $P C D H 15$ is a risk gene for psychiatric disorders. Reelin, which is encoded by RELN, is an extracellular matrix protein that regulates brain developmental processes, such as neuronal migration and dendrite formation, and modulates synaptic functions in adult brains (Ishii et al., 2016; Lee and D'Arcangelo, 2016). Reelin is associated with various psychiatric disorders such as SCZ, autism spectrum disorders, and BP (Folsom and Fatemi, 2013; Ishii et al., 2016). Two SCZ patients with exonic deletions in RELN have been reported in previous studies (Costain et al., 2013; Kushima et al., 2017).

In this study, to recapitulate the pathologies in BP and SCZ in vitro, we differentiated patient-derived iPSCs into neurons and identified a set of similar phenotypes among induced neurons derived from patients with different genetic lesions, which potentially represents a cell biological basis for shared clinical features between these two different disorders.

\section{Materials and Methods}

\section{Subjects}

A human subject was recruited at Keio University, and another from Kyushu University. Written informed consent for the present study was obtained from this patient. All the experimental procedures for biopsy, genetic analysis, and iPSC production were approved by the Keio University School of Medicine Ethics Committee (approval \#20080016), the Ethics Committee of Nagoya University (approval \#2010-1033-3 and \#2012-0184-14), and the Ethics Committee of Kyushu University (approval \#IRB30-537).

We recruited two patients with BP. The first patient (BP1) was a 43-year-old Japanese female with a family history of alcohol use disorder. Her developmental history was unremarkable. In her early thirties, she had depressive moods and suicidal thoughts. Although she was treated with antidepressant medications, a significant treatment effect was not observed. After 3 years, she received a diagnosis of bipolar I disorder because she had her first manic episode, which included an elevated mood, increased activity and talkativeness, and decreased need for sleep. In her late thirties, she became depressed again after she received a diagnosis of a malignant tumor. Her depressive symptoms were chronic and refractory to pharmacological treatments, requiring multiple hospitalizations. At the time of the study evaluation, she was receiving treatment with lithium and quetiapine.

The second patient (BP2) was a 57-year-old Japanese female with no remarkable developmental history and no family history of psychiatric disorders. She had been committed to various social activities and was sometimes hyperactive until her middle thirties (hypomanic episodes). Since her late thirties, she had experienced insomnia, depressive moods, and severe suicidal thoughts two or three times a year, requiring multiple hospitalizations. Despite treatment with antidepressant medications, a considerable treatment effect was not observed. After she had received a diagnosis of bipolar I disorder based on her life history and hyperactivity between depressive episodes, lithium was prescribed. However, the response was still poor. At age 50 years, lithium was completely replaced with valproate and lamotrigine. After that, her mood stabilized and no subsequent hospitalizations were necessary. At the time of the study evaluation, she was still receiving valproate and lamotrigine. Although she had once received a diagnosis of bipolar I disorder, the diagnosis was revised to bipolar II disorder because of the lack of severe manic episodes.

\section{iPSC generation and culture}

The 1210B2 (Nakagawa et al., 2014), 201B7 (Takahashi et al., 2007), WD39 (Imaizumi et al., 2012), 414C2 (Okita et al., 2011), eKA3 (Matsumoto et al., 2016), eTKA4 (Matsumoto et al., 2016), and NC1032-1-2 cell lines were used as the healthy control human iPSC lines. The NC1032-1-2 line was established from cells obtained from a healthy 30-year-old Japanese woman using episomal vectors as previously described (Okita et al., 2013), which was then used for establishment of the isogenic PCDH15-deleted iPSC line. iPSC lines derived from an SCZ patient with heterozygous RELN deletion (SCZ1-1, SCZ1-2) were established in a previous study (Arioka et al., 2018). BP patient-derived iPSCs (BP-iPSCs) were generated by a previously reported method (Okita et al., 2013; Hosoya et al., 2017). Briefly, episomal plasmids encoding six factors (OCT4, SOX2, KLF4, LIN28, L-MYC, $E B N A 1$, and dominant-negative $p 53$ ) were transduced into human peripheral blood mononuclear cells obtained from the patient. Established iPSCs were evaluated based on the expression of pluripotent markers, episomal transgene elimination, and the absence of clinically significant CNVs.

iPSCs were cultured with or without feeder cells. For on-feeder culture, iPSCs were grown on mitomycin-Ctreated SNL murine fibroblast feeder cells in standard human pluripotent stem cell medium (DMEM/F12 medium, FUJIFILM Wako Pure Chemical) containing 20\% KnockOut Serum Replacement (KSR; Thermo Fisher Scientific), $0.1 \mathrm{~mm}$ nonessential amino acids (NEAAs; Merck), $0.1 \mathrm{~mm}$ 2-mercaptoethanol (Merck), and $4 \mathrm{ng} / \mathrm{ml}$ fibroblast growth factor 2 (PeproTech) at $37^{\circ} \mathrm{C}$ in an atmosphere containing $3 \% \mathrm{CO}_{2}$. For the feeder-free culture, iPSCs 
were grown on tissue culture dishes coated with $1 \mu \mathrm{g} / \mathrm{ml}$ iMatrix-511 (Laminin-511 E8, Nippi). iPSCs were cultured in StemFit AK02N (Ajinomoto) at $37^{\circ} \mathrm{C}$ in an atmosphere containing $5 \% \mathrm{CO}_{2}$.

\section{Identification and validation of an exonic deletion of PCDH15}

Genomic DNA was extracted from blood or iPSC lines. To identify an exonic deletion of $P C D H 15$, we performed array comparative genomic hybridization $(\mathrm{aCGH})$ using an SurePrint G3 Human CGH Microarray, $2 \times 400 K$ (Agilent). The experiment was performed following the manufacturer instructions. CNV calls were made with Nexus Copy Number software version 9.0 (BioDiscovery) using the Fast Adaptive States Segmentation Technique 2 algorithm, which is a hidden Markov model-based approach. The log2 ratio thresholds for copy number loss and copy number gain were set at -0.7 and 0.45 , respectively. The significance threshold $p$ value was set at $1 \times 10^{-6}$, and at least four contiguous probes were required for CNV calls. To validate the exonic deletion of $P C D H 15$, quantitative real-time PCR was performed with TaqMan copy number assay (Hs03733966_cn for BP1 and Hs00117569_cn for BP2; Applied Biosystems). All genomic locations are given in NCBI36/hg18.

\section{In vitro three-germ differentiation via embryoid body formation}

To check the pluripotency of iPSCs, iPSCs treated with TrypLE Select (Thermo Fisher Scientific) were dissociated into single cells and plated in low-cell adhesion 96-well plates with V-bottomed conical wells. The cells were cultured in embryoid body (EB) medium (DMEM/F-12 containing 5\% KSR, 2 mM L-glutamine, 1\% NEAAs, and 0.1 $\mathrm{mm}$ 2-ME). On day 7, EBs were plated on culture plates coated with $0.1 \%$ gelatin (Merck) and $10 \mu \mathrm{g} / \mathrm{ml}$ fibronectin (Merck). The plated EBs were cultured for 3 weeks at $37^{\circ} \mathrm{C}$ in an atmosphere containing $5 \% \mathrm{CO}_{2}$.

\section{qRT-PCR}

RNA was extracted from the cells using the RNeasy Kit (Qiagen). One hundred nanograms of RNA was used to prepare cDNA using the iScript cDNA Synthesis Kit (BioRad). qRT-PCR was performed with SYBR Premix Ex Taqll (TaKaRa Bio) on the ViiA 7 real-time PCR system (Thermo Fisher Scientific). Values were normalized to GAPDH levels. The comparative $(\Delta \Delta \mathrm{Ct})$ method was used to analyze the data. Relative expression levels are presented as geometric means \pm geometric SDs. The primers used for qRT-PCR were as follows: GAPDH: forward, AATCCCATCACCATCTTCCA; reverse, TGGACTCCACGACGTACTCA; PCDH15 (set1): forward, GAGGCAGCCTTGGCAAGAAA; reverse, CTGTCGAAACATCTTCTGT CAAAGT; PCDH15 (set2): forward, GGGACCATGGTTGGTGTAAT; reverse, CACCTGTGATGTTATTAATTCCAAA; and RELN: forward, AGAAGGACAAGACTCACAATGCT; reverse, GCTTCACAACCCACCACAAT.

\section{Neuron differentiation via dual SMAD inhibitor- treated EB formation}

For dual SMAD inhibitor-treated EB (DSi-EB) formation, the cells were cultured in medium hormone mix (MHM; Shimazaki et al., 2001; Okada et al., 2004) containing B27 supplement (Thermo Fisher Scientific) with $5 \mu \mathrm{M}$ SB431542 (Tocris Bioscience), 150 nм LDN193189 (StemRD), and 2.5 $\mu \mathrm{M}$ IWP-2 (Merck; Imaizumi et al., 2015). On day 7, DSi-EBs were plated on culture plates coated with Matrigel (Corning). The medium was replaced every $3 \mathrm{~d}$.

\section{Plasmids construction}

The NEUROG2 expression vector (PB-TET-PHlox66FRT-NEUROG2; Matsushita et al., 2017) was a gift from Dr. Minoru S.H. Ko (Keio Uniersity,Tokyo, Japan). ASCL1 and DLX2 expression vectors [PB-P(tetO)-hAscl1pA-PGK-PuroTK-pA and PB-P(tetO)-hDLX2-pA-floxPGKneo$\mathrm{pA}$ ] were established by Gateway cloning (Thermo Fisher Scientific). First, three plasmids with att-cloning sites (pProF$\mathrm{PHtetO}_{2}$, pMK-pA-PGKpacTK-pA1, pMK-pA-floxPGKneo-pA) were constructed according to the manufacturer protocol for the MultiSite Gateway Three-Fragment Vector Construction Kit (Thermo Fisher Scientific) from pDONR-P4P1r and pDONRP2rP3. Primer sequences and templates are listed below, as follows:

pProF-PHtetO ${ }_{2}$ (template: PB-TET-PH; Matsushita et al., 2017), primers: ggggACAACTTTGTATagaaaaGTTG ttaattaagtcgacATTAAGTTGGGTAACGCCAGGG, ggggACTGCTTTTTTGTACAAACTTgcgatcgcGATGGCCGCCAC CGCGGAGGC); pMK-pA-PGKpacTK-pA1 (template: pUC19PGKpacDeltaTKpA), primers: ggggACAGCTTTCTTGTACAAAGTGGTTAATTAAGGATCGGCAATAAAAAGACAGAATAAAACGCACGGGTGTTGGGTCGT, gggACAACTITGTATAATAAAGTTGCCCGGGTGCATGCCTGCAGGTCGACTCTAGA);pMK-pA-floxPGKneo-pA (template: pL452), primers: ggggACAGCTTTCTTGtacaaaGTGGggatcggcaataaaaagacagaataaaacgcacgggtgttgggtcgttgttcGTCGACCTGCAGCCAAGCTATCGAATTCC, ggggACAACtttgtaTAATAAAGTTGgcggccgcTCTAGAACTAGTGGATCCCC).

Then, the entry vector pENTR-L4-P(tetO)-R1 was established from $\mathrm{pProF}-\mathrm{PHtetO}_{2}$ by restriction enzyme digestion with Pacl (New England Biolabs Japan) and Dral (TaKaRa Bio). The destination vector PB-DEST-R4R3 was established from the PB-TET plasmid (Addgene). PB-TET was digested with Sall (TaKaRa) and Xbal (TaKaRa) to be ligated with a Spel-Xhol-digested $c c d B$ fragment. Then, the two expression vectors were constructed by three-fragment LR cloning using the LR Clonase II enzyme (Thermo Fisher Scientific). PB-P(tetO)-hAscl1-pA-PGK-PuroTK-pA was constructed from four plasmids, as follows: pENTR-L4P(tetO)-R1, pENTR221-hASCL1 (DNAFORM), pMK-pAPGKpacTK-pA1, and PB-DEST-R4R3. PB-P(tetO)-hDLX2pA-floxPGKneo-pA was also constructed from the following four plasmids: pENTR-L4-P(tetO)-R1, pENTR/D-hDLX2 (RIKEN BRC), pMK-pA-floxPGKneopA, and PB-DESTR4R3.

\section{Neuronal differentiation by transcription factor overexpression}

Based on a previous study (Matsushita et al., 2017), NEUROG2-inducible iPSCs were established using the following 
vectors: PB-TET-PH-lox66FRT-NEUROG2, pCMV-HyPBasePGK-Puro (a gift from Dr. Kosuke Yusa, Wellcome Sanger Institute, Hinxton, U.K.), and PB-CAGrtTA3G-IH. These vectors were cotransfected into iPSCs using Gene Juice Transfection Reagent (Merck). The transfectants were cultured in StemFit AK02N containing $450 \mu \mathrm{g} / \mathrm{ml}$ hygromycin (FUJIFILM Wako Pure Chemical) and 0.1-1.0 $\mu \mathrm{g} / \mathrm{ml}$ puromycin (Merck). To establish ASCL1- and DLX2-inducible iPSCs, we used the following vectors: PB-P(tetO)-hAscl1-pA-PGK-PuroTK-pA, PB-P(tetO)-hDLX2-pA-floxPGKneo-pA, pCMV-HyPBasePGK-Puro, and PB-CAGrtTA3G-IH. These vectors were cotransfected into iPSCs using Gene Juice Transfection Reagent (Merck). The transfectants were cultured in StemFit AK02N containing $450 \mu \mathrm{g} / \mathrm{ml}$ hygromycin (FUJIFILM Wako Pure Chemical), 0.1-1.0 $\mu \mathrm{g} / \mathrm{ml}$ puromycin (Merck), and 100 $\mu \mathrm{g} / \mathrm{ml} \mathrm{G} 418$ (nacalai tesque).

Feeder-free cultured iPSCs were used for the induction of neuronal differentiation. The cells were dissociated and seeded on culture dishes coated with poly-L-lysine, iMatrix511 (Laminin-511 E8), and Laminin (R\&D Systems). To induce glutamatergic neurons, NEUROG2-transduced cells were cultured in induction medium [MHM+B27 containing Y27632, FUJIFILM Wako Pure Chemical; $10 \mu \mathrm{M}$ DAPT, Merck; $2.5 \mu \mathrm{M}$ IWP-2; and $2 \mu \mathrm{g} / \mathrm{ml}$ doxycycline (Dox), FUJIFILM Wako Pure Chemical] on day 0. For GABAergic neuron induction, ASCL1- and DLX2-transfected cells were cultured in induction medium with $80 \mathrm{ng} / \mathrm{ml}$ recombinant human sonic hedgehog (R\&D Systems). On day 5, the medium was replaced with neuron culture medium [MHM+B27 containing $20 \mathrm{ng} / \mathrm{ml}$ brain-derived neurotrophic factor (BDNF), R\&D Systems; $10 \mathrm{ng} / \mathrm{ml}$ glial cell line-derived neurotrophic factor (GDNF), Alomone Labs; $200 \mu \mathrm{M}$ L-ascorbic acid, Merck; and $100 \mu \mathrm{M}$ dibutyryl cyclic adenosine monophosphate, Merck] or function assay medium (BrainPhys Neuronal Medium and N2-A/SM1, STEMCELL Technologies; containing $20 \mathrm{ng} / \mathrm{ml}$ BDNF, $20 \mathrm{ng} / \mathrm{ml}$ GDNF, $200 \mu \mathrm{M}$ L-ascorbic acid, and $1 \mathrm{~mm}$ dibutyryl cyclic adenosine monophosphate) . Treatment with $2 \mu \mathrm{M}$ PD0332991 isethionate (Merck) was also performed for both types of neuron induction from day 5 to day 21. The medium was replaced every $4 \mathrm{~d}$ after day 5 .

\section{Immunocytochemistry}

Cells were fixed with $4 \%$ paraformaldehyde for $20 \mathrm{~min}$ at room temperature and then incubated with blocking buffer (PBS containing 2\% normal fetal bovine serum, 2\% normal goat serum, $2 \%$ bovine serum albumin, and $0.2 \%$ Triton $\mathrm{X}-100$ ) for $1 \mathrm{~h}$ at room temperature. Then, the cells were incubated overnight at $4^{\circ} \mathrm{C}$ with primary antibodies diluted with blocking buffer without Triton X-100. The cells were washed three times with PBS and then incubated with secondary antibodies with Alexa Fluor 488, Alexa Fluor 555, or Alexa Fluor 647 (1:1000; Thermo Fisher Scientific) and Hoechst 33342 (Merck) for 1-2 h at room temperature. After washing with PBS, the cells were examined with a BZ-9000 microscope (Keyence) and an IN Cell Analyzer 6000 (GE Healthcare). The following antibodies were used as the primary antibodies in this study: Oct4 (1:500; mouse, catalog \#sc-5279, Santa Cruz Biotechnology), Nanog (1:500; rabbit, RCAB0004PF, REPLP-
CELL), SSEA4 (1:500; mouse, catalog \#ab16287, Abcam), Tra1-60 (1:500; mouse, MAB4360, Millipore), $\beta$ Ill tubulin (1:500; mouse, T8660, Sigma-Aldrich), $\alpha$-fetoprotein (AFP; 1:250; mouse, MAB1368, R\&D Systems), $\alpha$-smooth muscle actin ( $\alpha$ SMA; 1:300; mouse, A2547, SigmaAldrich), microtubule-associated protein 2 (MAP2; 1:1000; rabbit, M4403, Merck), MAP2 (1:1000; mouse, AB5622, Millipore), vesicular glutamate transporter 2 (VGluT2; 1:500; mouse, ab79157, Abcam), GABA (1:500; rabbit, A2052, Sigma-Aldrich), Synapsin I (1:2000; rabbit, S193, Sigma-Aldrich), Homer I (1:500; mouse, 2a8, Synaptic Systems), and Gephyrin (1:500; mouse, 147111, Synaptic Systems).

\section{High-content image analysis}

For morphologic analysis, 96-well plates with V-bottomed conical wells containing $1 \mathrm{~EB}$ in each well were imaged on an IN Cell Analyzer 6000 using the $2 \times$ objective. EBs were identified based on the contrast with the background; from the EB images obtained, the area and form factor were calculated using IN Cell Developer Toolbox version 1.9 (GE Healthcare).

For fluorescence intensity analysis and neurite length analysis of the EBs, stained plates were imaged on an IN Cell Analyzer 6000 high-content cellular analysis system; only the field containing the EB was selectively collected from each well using the $2 \times$ objective, resulting in $1 \mathrm{~EB}$ being scored per well. For cell population assays and dendrite length analysis, stained plates were imaged with an IN Cell Analyzer 6000; a set of $5 \times 5$ fields was collected from each well using the $20 \times$ objective. For quantitative analysis of the synaptic puncta, stained plates were imaged with an IN Cell Analyzer 6000; a set of $6 \times 6$ fields was collected from each well using the $60 \times$ objective.

Analysis using IN Cell Developer Toolbox version 1.9 (GE Healthcare) began by identifying intact nuclei stained by the Hoechst dye, which were defined as traced nuclei that were $>50 \mu \mathrm{m}^{2}$ in surface area and with intensity levels that were typical and lower than the threshold brightness of pyknotic cells. Each traced nuclear region was then expanded by $50 \%$ and cross-referenced with an endodermal marker (AFP), a mesodermal marker ( $\alpha$ SMA), and an ectodermal marker ( $\beta$ III tubulin) for identification; from these images, the fluorescence intensity of each marker was calculated. Using the expanded nuclear region images, neuron markers ( $\beta$ III tubulin and MAP2), a glutamatergic neuron marker (VGluT2), and a GABAergic neuron marker (GABA) were identified; from these images, the percentage of each marker was calculated (for neural subtype markers stained as granules, the number of $\beta$ III tubulin ${ }^{+}$cells containing one or more of the markers was quantified). Using the above-described traced neuronal images of each cell, neurite length, dendrite length, and the number of synaptic puncta (Homer $\mathrm{I}^{+}$, Gephyrin ${ }^{+}$, and/or Synapsin $\mathrm{I}^{+}$puncta) were also analyzed.

\section{Microarray analysis}

RNA was extracted with the RNeasy Kit (QIAGEN), and the RNA quality and quantity were assessed using a bioanalyzer (model 2100, Agilent Technologies). Microar- 
Table 1. Used primers for generating isogenic $P C D H 15$ deletion iPSCs

\begin{tabular}{|c|c|c|}
\hline Targets & Primers & Sequence $\left(5^{\prime} \rightarrow 3\right)$ \\
\hline \multirow[t]{5}{*}{ sgRNAs construction } & sgRNA\#1-Fw & GAGACCACTTGGATCCGGACGGCAATCACGAGTGTTGTTTTAGAGCTAGAAATAGCA \\
\hline & sgRNA\#2-Fw & GAGACCACTTGGATCCGTCGCCTCTCATTCAGATTTGTITTAGAGCTAGAAATAGCA \\
\hline & sgRNA\#3-Fw & GAGACCACTTGGATCCGTGGCAGCTTGATAAGTGAGGTTITAGAGCTAGAAATAGCA \\
\hline & sgRNA\#4-Fw & GAGACCACTTGGATCCGCGCCTCTCATTCAGATTTTGTITIAGAGCTAGAAATAGCA \\
\hline & sgRNA\#5-Fw & GAGACCACTTGGATCCGCTCATTCAGATTTTGGGCAGTTTTAGAGCTAGAAATAGCA \\
\hline sgRNA\#universal-Rv & & $\begin{array}{l}\text { GCCCGGGTTTGAATTCAAAAAAAGCACCGACTCGGTGCCACTITTTCAAGTTGATAA } \\
\text { CGGACTAGCCTTATTTTAACTTGCTATTTCTAGCTCTAA }\end{array}$ \\
\hline \multirow[t]{2}{*}{ T7E1 assay } & Fw & CTCAGTTTACATCCTGACTCAACCAC \\
\hline & $\mathrm{Rv}$ & CCTTCAAACGGCCAAACATAATCTCC \\
\hline
\end{tabular}

Sequence information of the primers for sgRNAs construction and T7E1 assay. Fw, Forward primer; Rv, reverse primer. Also see Materials and Methods.

ray analysis was performed using the Clariom S Assay for humans (Thermo Fisher Scientific). The accession number was referred later. Data were analyzed by Transcriptome Analysis Console 4.0 (Thermo Fisher Scientific). Gene ontology (GO) and pathway analyses were performed using DAVID 6.8 Bioinformatics Resources (https://david. ncifcrf.gov). The data shown in this publication have been deposited in the NCBI Gene Expression Omnibus database (http://www.ncbi.nlm.nih.gov/geo/). The accession number of our microarray analysis data was GSE116820.

\section{Genetic engineering of PCDH15-mutant iPSCs}

PCDH15-deleted iPSCs were established using the CRISPR/Cas9 system, as previously described (Arioka et al., 2018). In brief, single-guide RNA (sgRNA) expression vectors were constructed using $\mathrm{pHL}-\mathrm{H} 1-\mathrm{ccdB}-$ $\mathrm{mEF} 1 \alpha-\mathrm{RiH}$ vector (catalog \#60601, Addgene) with two oligos containing the sgRNA target site and a universal reverse primer (Table 1). The T7 endonuclease I (T7E1) assay was performed using genomic DNA from HEK293FT cells co-transfected with the sgRNA expression vector and Cas9 expression vector (Addgene ID: $60599)$ to assess sgRNA activity. The target region of sgRNA was amplified from the genomic DNA using a specific primer set (Table 1). The PCR products were digested using T7E1 (New England Biolabs) after denaturing and reannealing. To establish the isogenic PCDH15-deleted iPSC line, sgRNA and Cas9 expression vectors were cotransfected into healthy control iPSCs, NC1032-1-2 (Control 1) and cells were selected with puromycin.

\section{Microelectrode array analysis}

The microelectrode array (MEA) was assayed using the Maestro system (Axion Biosystems). Neuronal inductions from iPSCs were performed in 48-well MEA plates coated with poly-L-lysine, iMatrix-511, and laminin. For neuronal differentiation, iPSCs were cultured in induction medium for the first $5 \mathrm{~d}$ and then in function assay medium from day 5 until day 28 or day 42 . Data were acquired using a sampling rate of $12.5 \mathrm{kHz}$ and filtered using a 200-3000 $\mathrm{Hz}$ Butterworth bandpass filter. The detection threshold was set to $+6.0 \times \mathrm{SD}$ of the baseline electrode noise. Five minutes of activity was subsequently recorded at $37^{\circ} \mathrm{C}$. Given the considerable variation in spike count between wells and plates, we focused on active electrodes (electrodes with an average of $>5$ spikes/min; Isoda et al.,
2016), which were certain to make contact with neurons. The number of active electrodes and the mean spike rate per active electrode (spikes per second) was calculated using the spike count file generated by the Axion Integrated Studio program (Axion Biosystems). The spike raster plot was generated by Neural Metric Tool (Axion Biosystems). To determine the responses to the agonist or antagonists of glutamate or the GABA receptor, $50 \mu \mathrm{M}$ CNQX (Tocris Bioscience), $50 \mu \mathrm{M}$ AP-5 (Alomone Labs), or $10 \mu \mathrm{M}$ GABA (nacalai tesque) was applied as treatment, and the activity was recorded.

\section{Calcium imaging}

Neurons were induced from iPSCs by culture in induction medium for $5 \mathrm{~d}$ followed by function assay medium from day 5 . Calcium imaging analyses were performed on days 28-30. Cells were loaded with $1 \mu \mathrm{g} / \mathrm{ml}$ fluo-8 AM (AAT Bioquest) in recording medium (20 mM HEPES, 115 $\mathrm{mm} \mathrm{NaCl}, 5.4 \mathrm{~mm} \mathrm{KCl}, 0.8 \mathrm{~mm} \mathrm{MgCl}_{2}, 1.8 \mathrm{~mm} \mathrm{CaCl}_{2}$, and $13.8 \mathrm{~mm}$ glucose; Dojindo) containing 0.02\% Cremophor EL (Dojindo) and incubated for $20 \mathrm{~min}$ at $37^{\circ} \mathrm{C}$ and $5 \%$ $\mathrm{CO}_{2}$. After washing with PBS, the medium was changed to the recording medium. Changes in fluorescence intensity were measured using an IX83 inverted microscope (Olympus) equipped with an Electron Multiplying CCD Camera (Hamamatsu Photonics) and LED illumination system pE-4000 (CoolLED). We recorded 3500 frames (1 frame: 31-32 ms) per well using the stream acquisition mode. MetaMorph Image Analysis Software (Molecular Devices) was used to analyze the live cell calcium traces. Regions of interest (ROIs) were drawn on cells based on time projection images of the recordings. ROI traces of the time course of changes in fluorescence intensity were generated and used as substrates for subsequent analyses. To adjust for photobleaching, the difference in intensity between the first frame and last frame was calculated and subtracted from the raw intensity. The change in fluorescence intensity over time was normalized as $\Delta F / F$ $=\left(F-F_{0}\right) / F_{0}$, where $F_{0}$ is fluorescence at the starting point of exposure (time 0$). \Delta F$ max was defined as the difference of the largest change of $\Delta F / F$ associated with each calcium spike.

\section{Statistical analysis}

Statistical analyses were performed using a Dunnett's or Tukey's test for multiple comparisons. For comparison between two groups, an unpaired Student's $t$ test or a 
paired $t$ test was used. All statistical analyses were performed using SAS 9.2 (SAS Institute). Probability values ( $p$ value) $<0.05$ were considered to be statistically significant. Statistical test results are included in Table 2.

\section{Results}

\section{Generation of iPSCs from BP patients}

$\mathrm{BP}$ and SCZ are distinct neuropsychiatric diseases but share a subset of similar pathologies and symptoms (Maggioni et al., 2017). To recapitulate the shared BP and SCZ pathologies in vitro, we prepared iPSCs derived from $\mathrm{BP}$ and SCZ patients to induce neurons (Fig. 1A). We focused on two BP patients (BP1 and BP2), who were evaluated in a high-resolution CNV analysis study (our unpublished observation). The patient characteristics are listed in Figure $1 B$ (see also Materials and Methods). Using aCGH, we identified an exonic deletion of $P C D H 15$ in each patient with BP (Fig. 1C). The coordinate of this deletion of BP1 was chr10:56,149,683-56,924,932, and the deletion of BP2 was chr10:54,162,953-55,694,398. The deletion of BP1 included exon 1 of most of the PCDH15 transcripts, and the deletion of BP2 included PCDH15 exon 9 to the last exon and MBL2 (mannose binding lectin 2). These $P C D H 15$ deletions were validated by the TaqMan copy number assay (Fig. 1D). We generated two iPSC clones (BP1-1, BP1-2) from BP1 and one iPSC clone (BP2-1) using episomal plasmids (see Materials and Methods), and we detected the same exonic deletions of $P C D H 15$ as those detected in blood cells (Fig. $1 C, D)$. Immunocytochemical analysis demonstrated that our newly established BP-iPSCs expressed the pluripotent markers Oct4, Nanog, SSEA4, and Tra1-60 (Fig. 1E). In vitro three-germ layer differentiation analysis via EBs also showed the differentiation potentials of the iPSCs into three germ layers (Fig. 1F). These results suggest that the BP-iPSCs conserved the patient's genetic background and had adequate pluripotency.

We also used two previously established iPSC clones (SCZ1-1 and SCZ1-2) derived from an SCZ patient with RELN deletion (SCZ1) (Fig. 1B; Arioka et al., 2018; Sobue et al., 2018) as SCZ patient-derived iPSCs (SCZ-iPSCs) in subsequent experiments.

\section{Ectoderm-enriched embryoid body and neuron formation by chemical treatment}

There are two major methods for neural differentiation from iPSCs or embryonic stem cells (ESCs). One is the chemical induction method, in which iPSCs are treated with several pharmacological agents or bioactive proteins for differentiation into neurons via EB or neurosphere formation (Han et al., 2011; Espuny-Camacho et al., 2013; Matsumoto et al., 2016). The other is the direct conversion method, involving the overexpression of specific transcription factors (Zhang et al., 2013; Colasante et al., 2015; Sun et al., 2016; Yang et al., 2017). To select the best method for recapitulating the disease-specific mature neuron phenotypes, we used both methods to differentiate iPSCs into neurons (Fig. 1A).

First, we performed chemical treatment. In previous studies, SCZ or BP patient-derived iPSCs exhibited ab- normal phenotypes of early-stage neural differentiation when this type of method was used (Madison et al., 2015; Toyoshima et al., 2016). We used BP-iPSCs (BP1-1, BP1-2) and SCZ-iPSCs (SCZ1-1, SCZ1-2) as patientderived iPSCs. To confirm whether such phenotypes occurred in our iPSC lines, neurons were induced via EB formation. First, we checked the potential of the two types of EB formation. Normal EBs were formed in EB medium (Fig. 2A). Another type of EB is induced by dual SMAD inhibition to facilitate neural differentiation (Chambers et al., 2009). DSi-EBs were induced in MHM with two DSis, namely, SB431542 and LDN193189 (Imaizumi et al., 2015; Matsumoto et al., 2016). The Wnt inhibitor IWP-2 was also used for DSi-EB formation to induce anterior regionality of the brain (Fig. 2A; Imaizumi et al., 2015; Nehme et al., 2018). Six clones of iPSCs (1210B2, 201B7, eKA3, eTKA4, WD39, and 414C2) were used as healthy control iPSCs. Each group of iPSCs formed EBs by both methods (Fig. 2B). To assess EB development, we examined morphometric parameters including size and form factor. The patient-derived iPSCs tended to form smaller and more distorted EBs than the control iPSCs, although there were no significant differences in size and form factor among EBs derived from each group of iPSC lines (Fig. 2C,D). In addition, the PCDH15 and RELN gene expression levels of DSi-EBs were analyzed by qRT-PCR. The expression of both genes did not change significantly between the control and BP or SCZ, although PCDH15 tended to exhibit low expression in BP samples and RELN exhibited a similar trend in SCZ samples (Fig. 2E).

To investigate whether neurons from the patientderived iPSCs exhibited aberrant phenotypes, we induced neural differentiation via DSi-EB formation. DSi-EBs were plated on culture plates on day 7. Plated DSi-EBs were cultured for up to an additional $15 \mathrm{~d}$ in MHM with DSi and IWP-2 (Fig. 2F). We used 1210B2 and 201B7 as control iPSCs, and BP-iPSCs (BP1-1, BP1-2) and SCZ-iPSCs (SCZ1-1, SCZ1-2) were used as patientderived iPSCs. Immunocytochemical analysis showed that the expression levels of markers of the three germ layers, namely, $\beta$ III tubulin (ectoderm), $\alpha \mathrm{SMA}$ (mesoderm), and AFP (endoderm), in the patient-derived cells did not differ significantly from those in the control cells (Fig. 2G). Thus, the capacity of differentiation into the three germ layers among the control and both patient-derived iPSCs was likely to be the same. We then measured the length of neurite extension from the cell clusters. To visualize the neurites, cells were immunostained for $\beta$ III tubulin. Binarized images were formed from stained images to quantify the total fiber length of each cell cluster (a) and fiber numbers of each cell cluster (b) of the $\beta$ III tubulin ${ }^{+}$cells (Fig. $2 H)$. Average neurite length was defined as $(a) /(b)$. The neurite lengths of patient-derived cells were significantly shortened from day 13 onward (Fig. $21, J$ ). We found that this method was not suitable for the analysis of mature neurons because of early-stage neuron abnormalities, although these phenotypes may reflect developmental abnormalities of the pathologies of BP and SCZ. Thus, we decided not to perform further analysis using this method. 
Table 2. $p$ Values of the indicated statistical comparisons

\begin{tabular}{|c|c|c|}
\hline Figures & Measurement & Type of test \\
\hline \multirow[t]{2}{*}{ Figure $2 C$} & EB size (EB) & Dunnett's test \\
\hline & EB size (DSi-EB) & Dunnett's test \\
\hline \multirow[t]{2}{*}{ Figure $2 D$} & EB form factor (EB) & Dunnett's test \\
\hline & EB form factor (DSi-EB) & Dunnett's test \\
\hline \multirow[t]{2}{*}{ Figure $2 E$} & PCDH15 gene expression & Dunnett's test \\
\hline & Reln gene expression & \\
\hline \multirow[t]{3}{*}{ Figure $2 G$} & Intensity/area ( $\beta$ III tubulin) & Dunnett's test \\
\hline & Intensity/area ( $\alpha \mathrm{SMA})$ & Dunnett's test \\
\hline & Intensity/area (AFP) & Dunnett's test \\
\hline \multirow[t]{4}{*}{ Figure $2 J$} & Neurite length (day 10) & Dunnett's test \\
\hline & Neurite length (day13) & Dunnett's test \\
\hline & Neurite length (day16) & Dunnett's test \\
\hline & Neurite length (day22) & Dunnett's test \\
\hline Figure $3 C$ & No. of cells $\left(\beta I I I\right.$ tubulin $\left.{ }^{+} / \mathrm{HO}^{+}\right)$ & Tukey's test \\
\hline
\end{tabular}

\begin{tabular}{|c|c|}
\hline comparison & $p$ Value \\
\hline Control vs BP1 & 0.4406 \\
\hline Control vs SCZ1 & 0.5982 \\
\hline Control vs BP1 & 0.5619 \\
\hline Control vs SCZ1 & 0.9784 \\
\hline Control vs BP1 & 0.5015 \\
\hline Control vs SCZ1 & 0.7476 \\
\hline Control vs BP1 & 0.0662 \\
\hline Control vs SCZ1 & 0.0562 \\
\hline Control vs BP1 & 0.3861 \\
\hline Control vs SCZ1 & 0.3897 \\
\hline Control vs BP1 & 0.7288 \\
\hline Control vs SCZ1 & 0.5178 \\
\hline Control vs BP1 & 0.9826 \\
\hline Control vs SCZ1 & 0.2543 \\
\hline Control vs BP1 & 0.9778 \\
\hline Control vs SCZ1 & 0.9238 \\
\hline Control vs BP1 & 0.7731 \\
\hline Control vs SCZ1 & 0.9345 \\
\hline Control vs BP1 & 0.7746 \\
\hline Control vs SCZ1 & 0.8824 \\
\hline Control vs BP1 & 0.0293 \\
\hline Control vs SCZ1 & 0.0324 \\
\hline Control vs BP1 & 0.0192 \\
\hline Control vs SCZ1 & 0.01 \\
\hline Control vs BP1 & 0.0036 \\
\hline Control vs SCZ1 & 0.0025 \\
\hline $1210 \mathrm{~B} 2$ vs $201 \mathrm{~B} 7$ & 0.9993 \\
\hline $1210 \mathrm{~B} 2$ vs BP1-1 & 1 \\
\hline $1210 \mathrm{~B} 2$ vs BP1-2 & 1 \\
\hline $1210 \mathrm{~B} 2$ vs BP2-1 & 0.0218 \\
\hline $1210 B 2$ vs SCZ1-1 & 0.5216 \\
\hline $1210 \mathrm{~B} 2$ vs SCZ1-2 & 0.875 \\
\hline $201 \mathrm{~B} 7$ vs BP1-1 & 0.9975 \\
\hline $201 \mathrm{~B} 7$ vs BP1-2 & 0.9989 \\
\hline $201 \mathrm{~B} 7$ vs BP2-1 & 0.0036 \\
\hline $201 B 7$ vs SCZ1-1 & 0.2079 \\
\hline $201 B 7$ vs SCZ1-2 & 0.5352 \\
\hline $\mathrm{BP} 1-1$ vs BP1-2 & 1 \\
\hline BP1-1 vs BP2-1 & 0.0077 \\
\hline BP1-1 vs SCZ1-1 & 0.4016 \\
\hline BP1-1 vs SCZ1-2 & 0.8143 \\
\hline BP1-2 vs BP2-1 & 0.0042 \\
\hline BP1-2 vs SCZ1-1 & 0.3116 \\
\hline BP1-2 vs SCZ1-2 & 0.7283 \\
\hline BP2-1 vs SCZ1-1 & 0.5238 \\
\hline BP2-1 vs SCZ1-2 & 0.1306 \\
\hline SCZ1-1 vs SCZ1-2 & 0.9847 \\
\hline $1210 \mathrm{~B} 2$ vs $201 \mathrm{~B} 7$ & 1 \\
\hline $1210 \mathrm{~B} 2$ vs BP1-1 & 0.6317 \\
\hline $1210 \mathrm{~B} 2$ vs BP1-2 & 0.9984 \\
\hline $1210 B 2$ vs BP2-1 & 0.6973 \\
\hline $1210 B 2$ vs SCZ1-1 & 0.9988 \\
\hline $1210 B 2$ vs SCZ1-2 & 0.9994 \\
\hline $201 \mathrm{~B} 7$ vs $\mathrm{BP} 1-1$ & 0.7153 \\
\hline $201 \mathrm{~B} 7$ vs BP1-2 & 1 \\
\hline $201 \mathrm{~B} 7$ vs BP2-1 & 0.7806 \\
\hline 201B7 vs SCZ1-1 & 1 \\
\hline 201B7 vs SCZ1-2 & 1 \\
\hline BP1-1 vs BP1-2 & 0.7807 \\
\hline BP1-1 vs BP2-1 & 1 \\
\hline BP1-1 vs SCZ1-1 & 0.8539 \\
\hline BP1-1 vs SCZ1-2 & 0.7703 \\
\hline $\mathrm{BP} 1-2$ vs $\mathrm{BP} 2-1$ & 0.8448 \\
\hline BP1-2 vs SCZ1-1 & 1 \\
\hline BP1-2 vs SCZ1-2 & 1 \\
\hline BP2-1 vs SCZ1-1 & 0.8955 \\
\hline BP2-1 vs SCZ1-2 & 0.8325 \\
\hline SCZ1-1 vs SCZ1-2 & 1 \\
\hline
\end{tabular}


Table 2. Continued

\begin{tabular}{|c|c|c|c|c|}
\hline \multirow[t]{22}{*}{ Figures } & Measurement & Type of test & comparison & $p$ Value \\
\hline & No. of cells (VGluT2 ${ }^{+} \beta$ III tubulin ${ }^{+} / \beta$ III tubulin ${ }^{+}$) & Tukey's test & $1210 \mathrm{~B} 2$ vs $201 \mathrm{~B} 7$ & 0.9629 \\
\hline & & & $1210 \mathrm{~B} 2$ vs BP1-1 & 0.2892 \\
\hline & & & $1210 \mathrm{~B} 2$ vs BP1-2 & 0.9885 \\
\hline & & & $1210 \mathrm{~B} 2$ vs BP2-1 & 0.8416 \\
\hline & & & 1210B2 vs SCZ1-1 & 0.6553 \\
\hline & & & 1210B2 vs SCZ1-2 & 0.9756 \\
\hline & & & $201 \mathrm{~B} 7$ vs BP1-1 & 0.7818 \\
\hline & & & 201B7 vs BP1-2 & 0.9999 \\
\hline & & & $201 \mathrm{~B} 7$ vs BP2-1 & 0.9996 \\
\hline & & & $201 B 7$ vs SCZ1-1 & 0.9859 \\
\hline & & & $201 B 7$ vs SCZ1-2 & 1 \\
\hline & & & $\mathrm{BP} 1-1$ vs BP1-2 & 0.5003 \\
\hline & & & $\mathrm{BP} 1-1$ vs BP2-1 & 0.9484 \\
\hline & & & BP1-1 vs SCZ1-1 & 0.9956 \\
\hline & & & BP1-1 vs SCZ1-2 & 0.6512 \\
\hline & & & $\mathrm{BP} 1-2$ vs $\mathrm{BP} 2-1$ & 0.9885 \\
\hline & & & BP1-2 vs SCZ1-1 & 0.9093 \\
\hline & & & BP1-2 vs SCZ1-2 & 1 \\
\hline & & & BP2-1 vs SCZ1-1 & 0.9998 \\
\hline & & & BP2-1 vs SCZ1-2 & 0.9975 \\
\hline & & & SCZ1-1 vs SCZ1-2 & 0.9616 \\
\hline \multirow[t]{8}{*}{ Figure $3 D$} & PCDH15 gene expression (iPS) & Dunnett's test & Control vs BP & 0.9527 \\
\hline & & & Control vs SCZ & 0.9354 \\
\hline & PCDH15 gene expression (neuron) & Dunnett's test & Control vs BP & 0.2862 \\
\hline & & & Control vs SCZ & 0.4102 \\
\hline & RELN gene expression (iPS) & Dunnett's test & Control vs BP & 0.1826 \\
\hline & & & Control vs SCZ & 0.3746 \\
\hline & RELN gene expression (neuron) & Dunnett's test & Control vs BP & 0.6918 \\
\hline & & & Control vs SCZ & 0.9941 \\
\hline \multirow[t]{41}{*}{ Figure $3 G$} & No. of cells $\left(\beta\right.$ III tubulin $\left.{ }^{+} / \mathrm{HO}^{+}\right)$ & Tukey's test & $1210 \mathrm{~B} 2$ vs $201 \mathrm{~B} 7$ & 0.98 \\
\hline & & & $1210 \mathrm{~B} 2$ vs BP1-1 & 0.9914 \\
\hline & & & $1210 \mathrm{~B} 2$ vs BP1-2 & 0.9863 \\
\hline & & & $1210 \mathrm{~B} 2$ vs BP2-1 & 0.4556 \\
\hline & & & $1210 B 2$ vs SCZ1-1 & 1 \\
\hline & & & 1210B2 vs SCZ1-2 & 0.9992 \\
\hline & & & $201 \mathrm{~B} 7$ vs BP1-1 & 0.7241 \\
\hline & & & 201B7 vs BP1-2 & 1 \\
\hline & & & $201 \mathrm{~B} 7$ vs BP2-1 & 0.1395 \\
\hline & & & $201 B 7$ vs SCZ1-1 & 0.9894 \\
\hline & & & 201B7 vs SCZ1-2 & 0.9993 \\
\hline & & & BP1-1 vs BP1-2 & 0.7192 \\
\hline & & & $\mathrm{BP} 1-1$ vs $\mathrm{BP} 2-1$ & 0.7873 \\
\hline & & & BP1-1 vs SCZ1-1 & 0.9536 \\
\hline & & & BP1-1 vs SCZ1-2 & 0.8677 \\
\hline & & & BP1-2 vs BP2-1 & 0.1102 \\
\hline & & & BP1-2 vs SCZ1-1 & 0.9937 \\
\hline & & & BP1-2 vs SCZ1-2 & 0.9998 \\
\hline & & & BP2-1 vs SCZ1-1 & 0.2366 \\
\hline & & & BP2-1 vs SCZ1-2 & 0.1646 \\
\hline & & & SCZ1-1 vs SCZ1-2 & 0.9999 \\
\hline & No. of cells $\left(\mathrm{MAP}^{+} / \beta \mathrm{III}\right.$ tubulin $\left.{ }^{+}\right)$ & Tukey's test & $1210 \mathrm{~B} 2$ vs $201 \mathrm{~B} 7$ & 0.9997 \\
\hline & & & $1210 \mathrm{~B} 2$ vs BP1-1 & 0.9897 \\
\hline & & & $1210 \mathrm{~B} 2$ vs BP1-2 & 0.9829 \\
\hline & & & $1210 \mathrm{~B} 2$ vs BP2-1 & 0.5806 \\
\hline & & & $1210 \mathrm{~B} 2$ vs SCZ1-1 & 0.9812 \\
\hline & & & 1210B2 vs SCZ1-2 & 0.9842 \\
\hline & & & $201 \mathrm{~B} 7$ vs BP1-1 & 1 \\
\hline & & & $201 \mathrm{~B} 7$ vs BP1-2 & 0.9998 \\
\hline & & & $201 \mathrm{~B} 7$ vs BP2-1 & 0.8884 \\
\hline & & & $201 B 7$ vs SCZ1-1 & 0.9037 \\
\hline & & & $201 B 7$ vs SCZ1-2 & 0.9149 \\
\hline & & & $\mathrm{BP} 1-1$ vs $\mathrm{BP} 1-2$ & 1 \\
\hline & & & $\mathrm{BP} 1-1$ vs $\mathrm{BP} 2-1$ & 0.902 \\
\hline & & & BP1-1 vs SCZ1-1 & 0.6069 \\
\hline & & & BP1-1 vs SCZ1-2 & 0.6541 \\
\hline & & & $\mathrm{BP} 1-2$ vs BP2-1 & 0.9712 \\
\hline & & & BP1-2 vs SCZ1-1 & 0.6265 \\
\hline & & & BP1-2 vs SCZ1-2 & 0.6636 \\
\hline & \multirow{2}{*}{\multicolumn{2}{|c|}{ (Continued) }} & BP2-1 vs SCZ1-1 & 0.0941 \\
\hline & & & & \\
\hline
\end{tabular}


Table 2. Continued

\begin{tabular}{|c|c|c|c|c|}
\hline \multirow[t]{24}{*}{ Figures } & Measurement & Type of test & comparison & $p$ Value \\
\hline & & & BP2-1 vs SCZ1-2 & 01225 \\
\hline & & & SCZ1-1 vs SCZ1-2 & 1 \\
\hline & No. of cells $\left(\mathrm{GABA}^{+} \beta\right.$ III tubulin ${ }^{+} / \beta$ III tubulin $\left.{ }^{+}\right)$ & Tukey's test & $1210 \mathrm{~B} 2$ vs $201 \mathrm{~B} 7$ & 0.9415 \\
\hline & & & $1210 \mathrm{~B} 2$ vs $\mathrm{BP} 1-1$ & 0.2961 \\
\hline & & & 1210B2 vs BP1-2 & 0.6938 \\
\hline & & & 1210B2 vs BP2-1 & 0.2707 \\
\hline & & & $1210 B 2$ vs SCZ1-1 & 0.343 \\
\hline & & & $1210 \mathrm{~B} 2$ vs SCZ1-2 & 0.8786 \\
\hline & & & $201 \mathrm{~B} 7$ vs $\mathrm{BP} 1-1$ & 0.9599 \\
\hline & & & $201 \mathrm{~B} 7$ vs BP1-2 & 0.9994 \\
\hline & & & $201 \mathrm{~B} 7$ vs BP2-1 & 0.949 \\
\hline & & & $201 B 7$ vs SCZ1-1 & 0.9747 \\
\hline & & & $201 B 7$ vs SCZ1-2 & 1 \\
\hline & & & $\mathrm{BP} 1-1$ vs BP1-2 & 0.9981 \\
\hline & & & BP1-1 vs BP2-1 & 1 \\
\hline & & & BP1-1 vs SCZ1-1 & 1 \\
\hline & & & BP1-1 vs SCZ1-2 & 0.9345 \\
\hline & & & BP1-2 vs BP2-1 & 0.9967 \\
\hline & & & BP1-2 vs SCZ1-1 & 0.9994 \\
\hline & & & BP1-2 vs SCZ1-2 & 0.9993 \\
\hline & & & BP2-1 vs SCZ1-1 & 1 \\
\hline & & & BP2-1 vs SCZ1-2 & 0.9169 \\
\hline & & & SCZ1-1 vs SCZ1-2 & 0.9587 \\
\hline \multirow[t]{8}{*}{ Figure $3 H$} & PCDH15 gene expression (iPS) & Dunnett's test & Control vs BP & 0.2334 \\
\hline & & & Control vs SCZ1 & 0.8567 \\
\hline & PCDH15 gene expression (neuron) & Dunnett's test & Control vs BP & 0.3458 \\
\hline & & & Control vs SCZ & 0.5146 \\
\hline & RELN gene expression (iPS) & Dunnett's test & Control vs BP & 0.999 \\
\hline & & & Control vs SCZ & 0.9874 \\
\hline & RELN gene expression (neuron) & Dunnett's test & Control vs BP & 0.081 \\
\hline & & & Control vs SCZ & 0.0663 \\
\hline \multirow[t]{2}{*}{ Figure $5 D$} & Dendrite length & Dunnett's test & Control vs BP & 0.0001 \\
\hline & & & Control vs SCZ & 0.0002 \\
\hline \multirow[t]{6}{*}{ Figure $5 E$} & Homer I puncta No. & Dunnett's test & Control vs BP & 0.0093 \\
\hline & & & Control vs SCZ & 0.009 \\
\hline & Synapsin I puncta No. & Dunnett's test & Control vs BP & 0.0067 \\
\hline & & & Control vs SCZ & 0.0014 \\
\hline & Homer I-Synapsin I puncta No. & Dunnett's test & Control vs BP & 0.0182 \\
\hline & & & Control vs SCZ & 0.0117 \\
\hline \multirow[t]{2}{*}{ Figure $5 H$} & Dendrite length & Dunnett's test & Control vs BP & 0.004 \\
\hline & & & Control vs SCZ & 0.0016 \\
\hline \multirow[t]{6}{*}{ Figure $5 I$} & Gephyrin puncta No. & Dunnett's test & Control vs BP & 0.0065 \\
\hline & & & Control vs SCZ & 0.0048 \\
\hline & Synapsin I puncta No. & Dunnett's test & Control vs BP & 0.0173 \\
\hline & & & Control vs SCZ & 0.0099 \\
\hline & Gephyrin-Synapsin I puncta No. & Dunnett's test & Control vs BP & 0.0044 \\
\hline & & & Control vs SCZ & 0.0042 \\
\hline \multirow[t]{2}{*}{ Figure $6 E$} & Gene expression of $P C D H 15$ & Student's $t$ test & Control 1 vs PCDH15del (glutamatergic neurons) & 0.1757 \\
\hline & & & Control 1 vs PCDH15del (GABAergic neurons) & 0.01 \\
\hline \multirow[t]{2}{*}{ Figure $6 G$} & Gene expression of RELN & Student's $t$ test & Control 2 vs RELNdel (glutamatergic neurons) & $<0.0001$ \\
\hline & & & Control 2 vs RELNdel (GABAergic neurons) & 0.0014 \\
\hline \multirow[t]{6}{*}{ Figure $7 B$} & No. of cells $\left(\beta I I I\right.$ tubulin $\left.{ }^{+} / \mathrm{HO}^{+}\right)$ & Student's $t$ test & Control 1 vs $\mathrm{PCDH} 15 \mathrm{del}$ & 0.1781 \\
\hline & & & Control 1 vs RELNdel & 0.2969 \\
\hline & No. of cells $\left(\mathrm{MAP}^{+} / \beta \mathrm{III}\right.$ tubulin $\left.{ }^{+}\right)$ & Student's $t$ test & Control 1 vs PCDH15del & 0.0003 \\
\hline & & & Control 1 vs RELNdel & 0.2568 \\
\hline & No. of cells (VGluT2 $2^{+} \beta$ III tubulin ${ }^{+} / \beta$ III tubulin ${ }^{+}$) & Student's $t$ test & Control 1 vs PCDH15del & 0.0098 \\
\hline & & & Control 1 vs RELNdel & 0.2754 \\
\hline \multirow[t]{2}{*}{ Figure $7 C$} & Dendrite length & Student's $t$ test & Control 1 vs $\mathrm{PCDH} 15 \mathrm{del}$ & 0.0418 \\
\hline & & & Control 1 vs RELNdel & 0.063 \\
\hline \multirow[t]{6}{*}{ Figure $7 D$} & Homer I puncta No. & Student's $t$ test & Control 1 vs $\mathrm{PCDH} 15 \mathrm{del}$ & 0.0282 \\
\hline & & & Control 1 vs RELNdel & 0.0209 \\
\hline & Synapsin I puncta No. & Student's $t$ test & Control 1 vs PCDH15del & 0.2101 \\
\hline & & & Control 1 vs RELNdel & 0.3278 \\
\hline & Homer I-Synapsin I puncta No. & Student's $t$ test & Control 1 vs PCDH15del & 0.982 \\
\hline & & & Control 1 vs RELNdel & 0.7786 \\
\hline Figure $7 F$ & No. of cells $\left(\beta I I I\right.$ tubulin $\left.{ }^{+} / \mathrm{HO}^{+}\right)$ & & Control 1 vs PCDH15del & 0.1441 \\
\hline & & & Control 1 vs RELNdel & 0.1954 \\
\hline & No. of cells $\left(\mathrm{MAP}^{+} / \beta \mathrm{III}\right.$ tubulin ${ }^{+}$) & & Control 1 vs $\mathrm{PCDH} 15 \mathrm{del}$ & 0.0281 \\
\hline & & & Control 1 vs RELNdel & 0.4007 \\
\hline & & (Continued) & & \\
\hline
\end{tabular}


Table 2. Continued

\begin{tabular}{|c|c|c|c|c|}
\hline \multirow[t]{3}{*}{ Figures } & Measurement & Type of test & comparison & $p$ Value \\
\hline & No. of cells $\left(\mathrm{GABA}^{+} \beta\right.$ III tubulin ${ }^{+} / \beta$ III tubulin ${ }^{+}$) & & Control 1 vs PCDH15del & 0.1269 \\
\hline & & & Control 1 vs RELNdel & 0.66 \\
\hline \multirow[t]{2}{*}{ Figure $7 G$} & Dendrite length & Student's $t$ test & Control 1 vs PCDH15del & 0.0055 \\
\hline & & & Control 1 vs RELNdel & 0.9907 \\
\hline \multirow[t]{6}{*}{ Figure $7 \mathrm{H}$} & Gephyrin puncta No. & Student's $t$ test & Control 1 vs PCDH15del & 0.553 \\
\hline & & & Control 1 vs RELNdel & 0.0452 \\
\hline & Synapsin I puncta No. & Student's $t$ test & Control 1 vs PCDH15del & 0.2637 \\
\hline & & & Control 1 vs RELNdel & 0.0431 \\
\hline & Gephyrin-Synapsin I puncta No. & Student's $t$ test & Control 1 vs PCDH15del & 0.5136 \\
\hline & & & Control 1 vs RELNdel & 0.3123 \\
\hline \multirow[t]{16}{*}{ Figure $8 B$} & Dendrite length (Glutamatergic neurons) & Dunnett's test & Control vs BP & 0.0001 \\
\hline & & & Control vs SCZ & 0.0002 \\
\hline & Homer I puncta No. & Dunnett's test & Control vs BP & 0.0003 \\
\hline & & & Control vs SCZ & 0.001 \\
\hline & Synapsin I puncta No. & Dunnett's test & Control vs BP & 0.0011 \\
\hline & & & Control vs SCZ & 0.0012 \\
\hline & Homer I-Synapsin I puncta No. & Dunnett's test & Control vs BP & $<0.0001$ \\
\hline & & & Control vs SCZ & $<0.0001$ \\
\hline & Dendrite length (GABAergic neurons) & Dunnett's test & Control vs BP & 0.0021 \\
\hline & & & Control vs SCZ & 0.0027 \\
\hline & Gephyrin puncta No. & Dunnett's test & Control vs BP & 0.0002 \\
\hline & & & Control vs SCZ & 0.0011 \\
\hline & Synapsin I puncta No. & Dunnett's test & Control vs BP & 0.1728 \\
\hline & & & Control vs SCZ & 0.1023 \\
\hline & Gephyrin-Synapsin I puncta No. & Dunnett's test & Control vs BP & $<0.0001$ \\
\hline & & & Control vs SCZ & $<0.0001$ \\
\hline \multirow[t]{5}{*}{ Figure $8 E$} & Spike frequency & Dunnett's test & Control vs BP (day28) & 0.8839 \\
\hline & & & Control vs SCZ (day28) & 0.924 \\
\hline & & & Control vs BP (day42) & 0.7486 \\
\hline & & & Control vs SCZ (day42) & 0.9812 \\
\hline & & Paired $t$ test & day 28 vs day 42 & 0.0104 \\
\hline \multirow[t]{5}{*}{ Figure $8 F$} & Spike frequency & Dunnett's test & Control 1 vs PCDH15del (day28) & 0.6129 \\
\hline & & & Control 2 vs RELNdel (day28) & 0.7575 \\
\hline & & & Control 1 vs PCDH15del (day42) & 0.2678 \\
\hline & & & Control 2 vs RELNdel (day42) & 0.9187 \\
\hline & & Paired $t$ test & day 28 vs day 42 & 0.0483 \\
\hline \multirow[t]{6}{*}{ Figure $8 G$} & Spike number ratio (CNQX) & Dunnett's test & Control vs BP & 0.0351 \\
\hline & & & Control vs SCZ & 0.0479 \\
\hline & Spike number ratio (AP-5) & & Control vs BP & 0.1922 \\
\hline & & & Control vs SCZ & 0.1165 \\
\hline & Spike number ratio (GABA) & & Control vs BP & 0.1204 \\
\hline & & & Control vs SCZ & 0.0071 \\
\hline \multirow[t]{10}{*}{ Figure 81} & $\Delta \mathrm{Fmax}$ & Dunnett's test & 1210B2 vs BP1-1 & 0.9215 \\
\hline & & & 1210B2 vs BP1-2 & 0.9233 \\
\hline & & & 1210B2 vs BP2-1 & 1 \\
\hline & & & $1210 \mathrm{~B} 2$ vs SCZ1-1 & 0.9999 \\
\hline & & & $1210 B 2$ vs SCZ1-2 & 0.9997 \\
\hline & Spike frequency & Dunnett's test & 1210B2 vs BP1-1 & 0.2334 \\
\hline & & & 1210B2 vs BP1-2 & 0.7435 \\
\hline & & & 1210B2 vs BP2-1 & 0.9984 \\
\hline & & & $1210 B 2$ vs SCZ1-1 & 0.9985 \\
\hline & & & $1210 B 2$ vs SCZ1-2 & 1 \\
\hline \multirow[t]{4}{*}{ Figure $8 \mathrm{~J}$} & $\Delta F \max$ & Student's $t$ test & Control 1 vs PCDH15del & 0.7346 \\
\hline & & & Control 1 vs RELNdel & 0.5067 \\
\hline & Spike frequency & Student's $t$ test & Control 1 vs PCDH15del & 0.0795 \\
\hline & & & Control 1 vs RELNdel & 0.3771 \\
\hline
\end{tabular}

$p$ Values $<0.05$ were considered to be statistically significant in this study.

\section{Neuronal differentiation of iPSCs by overexpression of transcription factors}

We next tested the direct method for neuronal conversion of iPSCs by transcription factor overexpression. This method can induce specific neuron subtypes. Previous studies have shown that Neurog2 overexpression induced glutamatergic neuron differentiation (Zhang et al., 2013), and co-overexpression of ASCL1 and DLX2 induced GABAergic neuron differentiation (Yang et al., 2017). Although these studies used lentivirus as a tool for introducing transcription factors, use of the PiggyBac transposon vector system enabled the establishment of transgenic cells that can be easily stored and used for experiments. One report using the PiggyBac system for the introduction of transcription factors into human ESCs resulted in highly efficient neural differentiation (Matsushita et al., 2017). Therefore, we established transgenic iPSC lines in which transcription factors can be induced by Dox. We used 1210B2 and 201B7 as healthy control iPSCs, while we used BP-iPSCs (BP1-1, BP1-2, and 
A

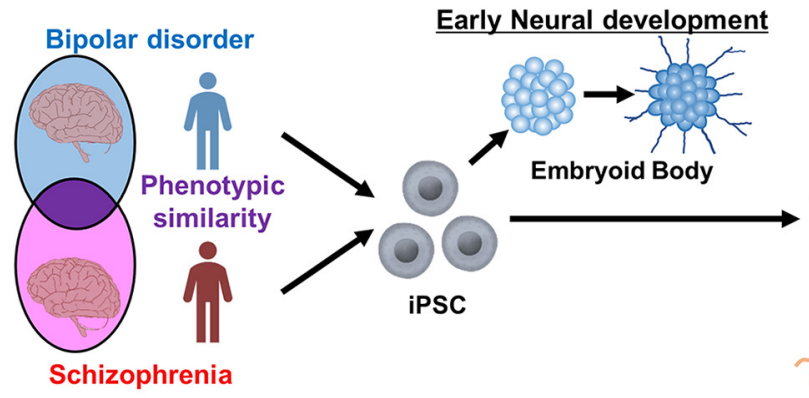

Mature Neuron

Glutamatergic neuron

GABAergic neuron

B

\begin{tabular}{|c|c|c|c|}
\hline Subject & BP1 & BP2 & SCZ1 \\
\hline Diagnosis & Bipolar I disorder & Bipolar II disorder & Schizophrenia \\
\hline Sex & Female & Female & Male \\
\hline Age & 43 & 57 & 58 \\
\hline Lithium response & poor & poor & \\
\hline
\end{tabular}

C

$\longleftarrow$ PCDH15 $\longrightarrow$

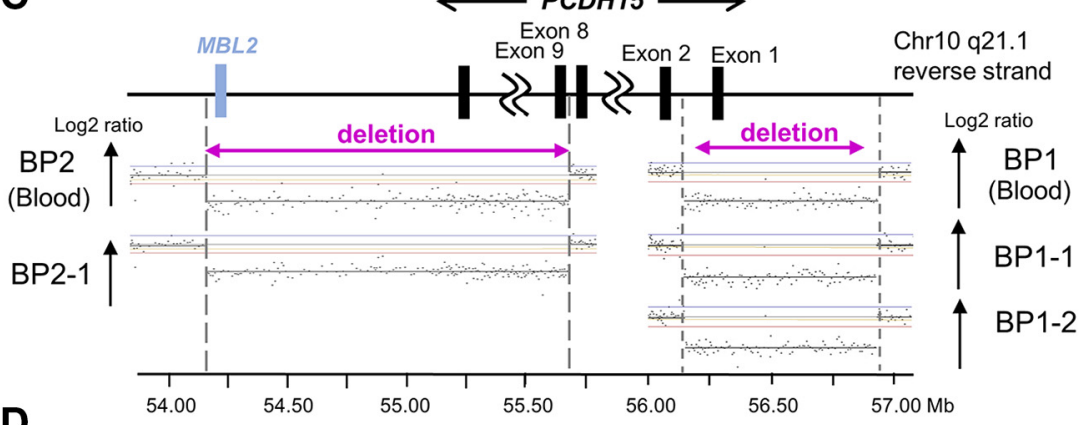

D
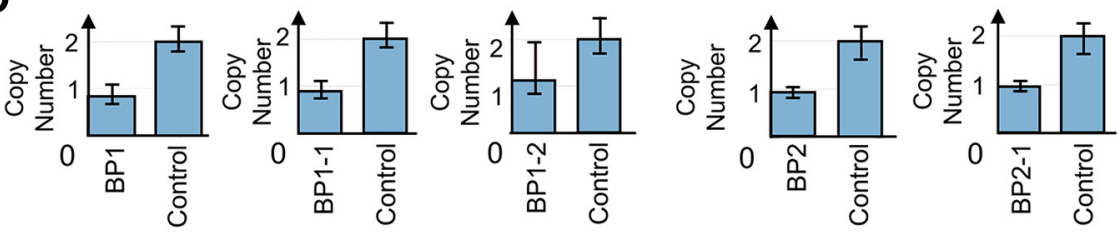

E
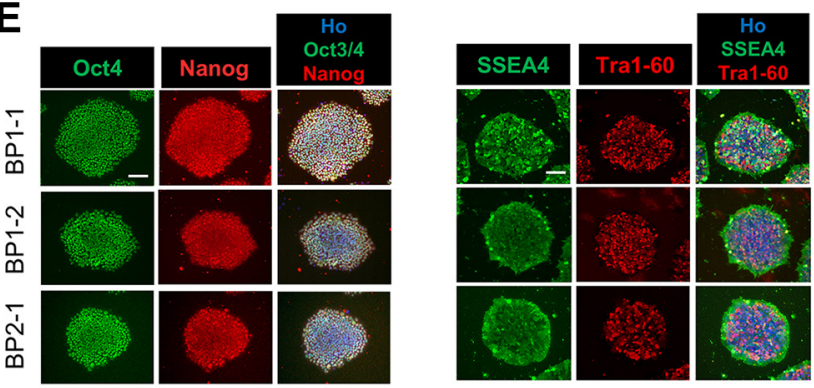

F

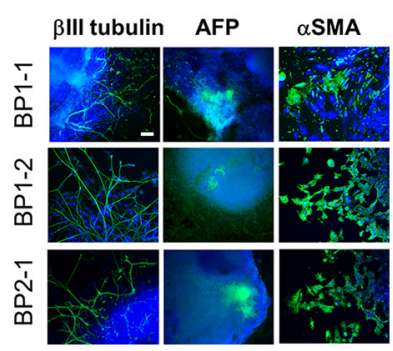

Figure 1. Generation and characterization of iPSCs derived from a BP patient. $\boldsymbol{A}$, Schematic diagram of the strategy to explore the phenotypes of BP and SCZ in vitro. B. Subjects list containing basic information. $\boldsymbol{C}, \mathrm{CNV}$ s in chromosome 10 were detected in blood and iPSCs derived from two BP patients by aCGH. $\boldsymbol{D}$. The exonic deletions of $P C D H 15$ identified in this study were validated by the TaqMan copy number assays. Bars indicate copy numbers predicted by the TaqMan copy number assays. Capped bars indicated the minimum and maximum copy number calculated for the sample replicate group $(n=4)$. Controls carried no aCGH-detected CNVs of PCDH15 (copy number $=2$ ) and were used to calibrate the assays. $\boldsymbol{E}$, The generated iPSCs expressed the pluripotent markers Oct4, Nanog, SSEA4, and Tra1-60. Scale bar, $100 \mu \mathrm{m}$. $\boldsymbol{F}$, Representative images of immunocytochemical analysis for in vitro three-germ layer differentiation. $\beta$ III-Tubulin, $\alpha$ SMA, and AFP are pluripotent markers of the ectoderm, mesoderm, and endoderm, respectively. Blue indicates $\mathrm{Ho}$, and green indicates the pluripotent marker. Scale bar, $100 \mu \mathrm{m}$.

BP2-1) and SCZ-iPSCs (SCZ1-1, SCZ1-2) as patientderived iPSCs. NEUROG2 expression vector-transduced iPSCs were established for glutamatergic neuronal induction, and Ascl1- and DLX2-transduced iPSCs were established for GABAergic neuronal induction (see Materials and Methods). The iPSCs were treated with Dox for $5 \mathrm{~d}$ and cultured in MHM for $28 \mathrm{~d}$ (Fig. 3A,E). Immunocytochemical analysis showed that the neuronal marker $\beta$ III tubulin was expressed in most of the cells induced from control iPSCs (control neurons), BP-iPSCs (BP neurons), 
A

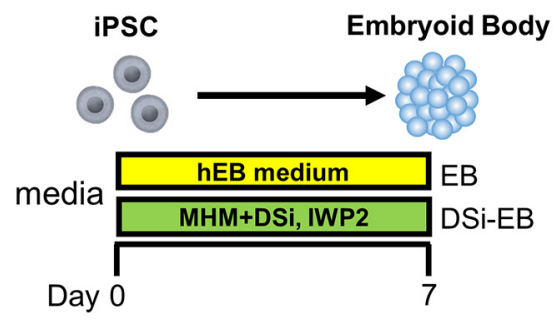

C

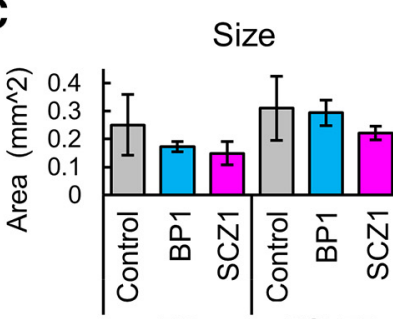

EB
D Form factor

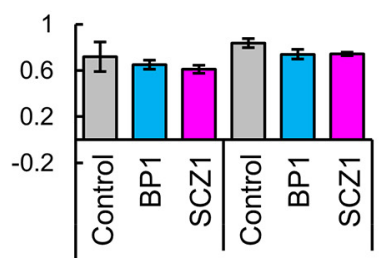

B

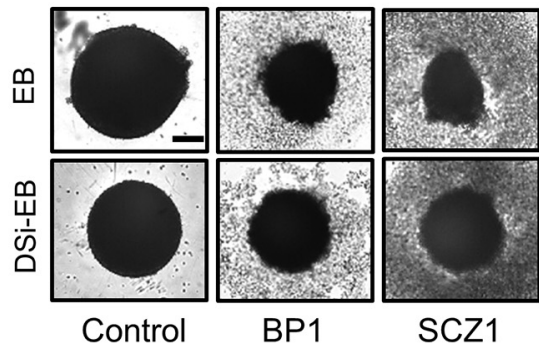

E

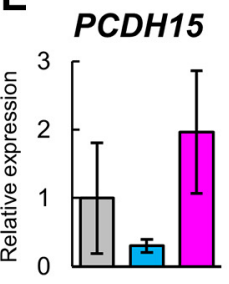

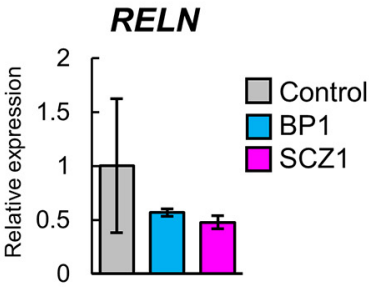

EB

DSi-EB

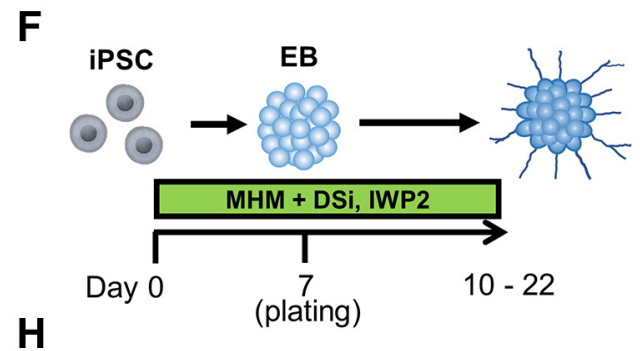

G
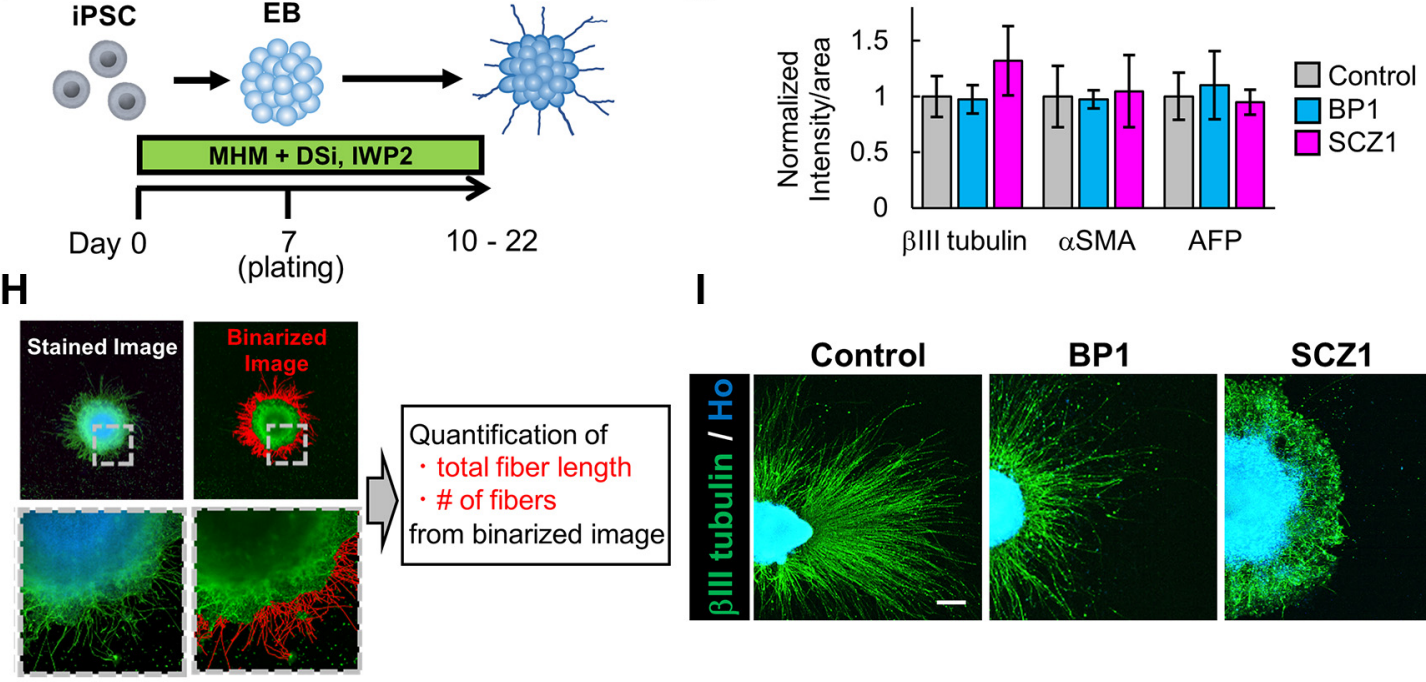

I

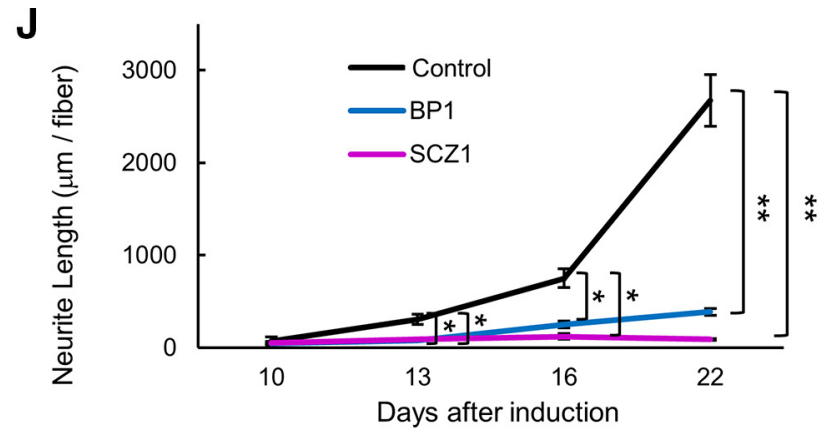

Figure 2. Neuron differentiation via EB formation. A, Overview of the protocol for EB formation. DSi represents SB431542 and LDN193189. B, Representative images of EBs on day 7. Scale bar, $200 \mu \mathrm{m}$. C, Quantification of EB sizes ( $n=3$ independent experiments; mean \pm SD; Dunnett's test, no significant differences were observed). $\boldsymbol{D}$, The form factor of the EBs was calculated as an indicator of roundness. $\boldsymbol{E}$, Gene expression of iPSCs and DSi-EBs. $\boldsymbol{E}$, Relative gene expression levels of $P C D H 15$ and RELN in DSi-EBs derived from six control lines, two BP lines (BP1-1 and BP1-2), and two SCZ lines (SCZ1-1 and SCZ1-2; $n=3$ independent experiments; mean \pm SD; Dunnett's test). Values were normalized to that of the control, which was considered to be 1.0. One sample of 1210B2-derived DSi-EBs, in which PCDH15 expression was under the detection limit, was removed from the analysis. $\boldsymbol{F}$, Overview of the protocol for neuron differentiation via EB formation. DSi represents SB431542 and LDN193189. G, Intensity levels of three germ layer markers, namely, $\beta$ III-tubulin, $\alpha$ SMA, and AFP. Intensity levels were normalized to that of the control, which was considered to be 1.0 ( $n=3$ independent experiments; mean \pm SD; Dunnett's test among each group, no significant differences were observed). 
continued

$\boldsymbol{H}$, Schematic diagram of the analysis protocol. Fiber length and number of $\beta$ III tubulin ${ }^{+}$cells were quantified from binarized image data obtained from stained images. I, Representative images of $\beta$ III-tubulin ${ }^{+}$neurons. Scale bar, $300 \mu \mathrm{m}$. J, Time-dependent changes of $\beta$ III-tubulin ${ }^{+}$mean neurite length per neurite fiber ( $n=3$ independent experiments; mean \pm SD; $* p<0.05, * * p<0.01$; Dunnett's test among each group). Mean neurite length is shown as the mean length of $\beta$ Ill-tubulin ${ }^{+}$neurite fiber.

and SCZ-iPSCs (SCZ neurons; Fig. 3B,C,F,G). The conversion efficiency of iPSCs into $\beta$ III tubulin ${ }^{+}$neurons was close to $100 \%$ in all lines, except line BP2-1 which still showed $>80 \%$ efficiency (Fig. $3 C$ ). $\beta$ III tubulin ${ }^{+}$neurons derived from NEUROG2-transduced iPSCs expressed the mature neuronal marker MAP2 and the glutamatergic neuronal marker VGLUT2 at similar ratios in each line (Fig. $3 B, C)$. Next, the PCDH15 and RELN gene expression levels of NEUROG2-transduced cells (iPSCs and induced glutamatergic neurons) were analyzed by qRT-PCR. We used the primer sets targeting the deletion of $P C D H 15$ in BP1 or RELN in SCZ1. Both PCDH15 and RELN were substantially upregulated on neuronal induction but were not differentially expressed between control, BP, SCZ iPSCs, or neurons (Fig. 3D). Induced neurons derived from ASCL1- and DLX2-transduced iPSCs expressed MAP2 and the GABAergic neuronal marker GABA at similar ratios in each line (Fig. 3F,G). The PCDH15 and RELN gene expression levels of ASCL1- and DLX2-cotransduced cells (iPSCs and induced GABAergic neurons) are shown in Figure $3 H$. The expression of both genes was upregulated in GABAergic neurons compared with undifferentiated iPSCs. Neither PCDH15 nor RELN expression changed significantly in patient-derived cells. These results showed that this method enabled both healthy and patient-derived iPSCs to efficiently differentiate into subtype-specific and mature neurons. Thus, we chose this method for further analyses.

\section{Characterization of gene expression in neurons induced from iPSCs}

To identify the characteristics of neurons induced from patient-derived iPSCs, the global gene expression profiles of neurons induced from control-iPSCs (1210B2 and 201B7) and patient-derived iPSCs (BP1-1, BP1-2, SCZ1-1, and SCZ1-2) were examined by a microarray analysis. Principal component analysis (PCA; Fig. 4A,E) and hierarchical analysis (Fig. $4 B, F$ ) showed that the control, BP, and SCZ neurons were placed in different groups. In particular, the profiles of the BP and SCZ neurons were closer to each other than to that of the control neurons (Fig. 4B,F). We next identified the differentially expressed genes (DEGs) in neurons induced from patient-derived iPSCs compared with control neurons (fold change, >2.0). We identified 1812 genes of BP glutamatergic neurons and 2382 genes of SCZ glutamatergic neurons that were upregulated or downregulated compared with the control neurons (Fig. 4C). For the GABAergic neurons, the expression levels of 1703 genes of BP neurons and 2357 genes of SCZ neurons were changed (Fig. 4G). To explore the cellular functions associated with the DEGs in the BP and SCZ neurons, GO analysis and pathway analysis were performed. Featured GO terms and pathways of common DEGs between BP and SCZ are shown in Figure 4, $D$ and $H$. In both glutamatergic and GABAergic neurons, multiple GO terms and pathways related to cell adhesion and neural function were enriched compared with control neurons (Fig. 4D,H).

\section{Neurons induced from patient-derived iPSCs exhibited shorter dendrites and reduced formation of excitatory and inhibitory synapses}

Microarray and GO analyses suggested that genes involved in cell adhesion may contribute to pathogenetic mechanisms (Fig. 4). Cell adhesion is a key event for neurite extension and synapse formation (Kiryushko et al., 2004; Missler et al., 2012). In addition, previous studies using postmortem human brains showed reduced spine density and dendrite length in the brains of BP and SCZ patients (Glantz and Lewis, 2000; Konopaske et al., 2014). To investigate whether BP and SCZ neurons have similar phenotypes, we determined the dendrite lengths and synaptic densities of induced neurons by immunocytochemical analysis with an IN Cell Analyzer 6000. Dendrite length was measured as the length of the region immunostained with the dendrite marker MAP2 (Fig. 5A). Then, to detect the number of morphological synapses in glutamatergic neurons, we counted the puncta of Synapsin I and Homer I as presynaptic or postsynaptic markers. For GABAergic neurons, we determined the number of puncta positive for Synapsin I and Gephyrin, which is a postsynaptic scaffolding protein found in GABAergic synapses (Fig. 5A). $\mathrm{MAP2}^{+}$dendrites of BP and SCZ neurons were significantly shorter than those of control neurons in both glutamatergic and GABAergic neurons (Fig. 5B,D,F,H). In addition, fewer puncta of Homer I and Synapsin I on glutamatergic neurons were detected in BP and $\mathrm{SCZ}$ neurons than in control neurons (Fig. 5C,E). The number of puncta of GABAergic Synapsin I and Gephyrin were also reduced in $\mathrm{BP}$ and $\mathrm{SCZ}$ neurons compared with control neurons (Fig. 5G,l). Moreover, the number of colocalized puncta between presynaptic and postsynaptic markers was also significantly decreased in BP and SCZ neurons (Fig. 5E,I). Thus, the number of synapses decreased in both BP and SCZ neurons. These results suggest that neurons induced from patient-derived iPSCs exhibit synapse- and dendrite-related phenotypes that are consistent with the phenotypes often observed in patients with psychiatric disorders and can thus serve as disease models of psychiatric disorders in vitro.

\section{Establishment of isogenic PCDH15-deleted iPSCs}

It is difficult to perform large-scale analyses because of the infrequency of patients carrying particular CNVs. Moreover, line-to-line variability caused by different genetic backgrounds complicate genotype-phenotype correlation. Thus, we sought to establish mutant and control iPSCs by targeted genome editing using the CRISPR/ 
A

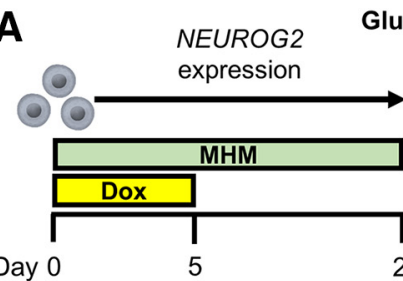

B

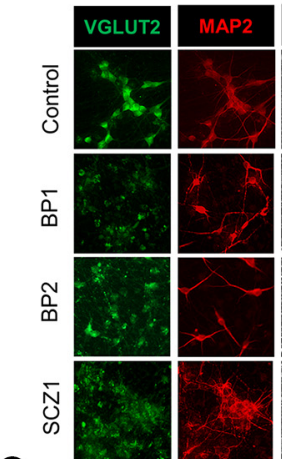

C

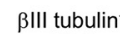

$/ \mathrm{Ho}^{+}$
Glutamatergic neuron

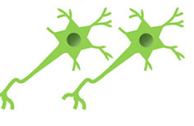

28

Ho

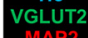

Bill tubulin

BIII tubulin
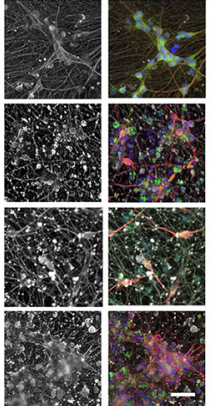

$\mathrm{MAP2}^{+}$

MAP2 $^{+}$
/ $\beta$ III tubulin

VGLUT2 $^{+} \beta$ III tubulin ${ }^{+}$ / $\beta$ III tubulin ${ }^{+}$

E

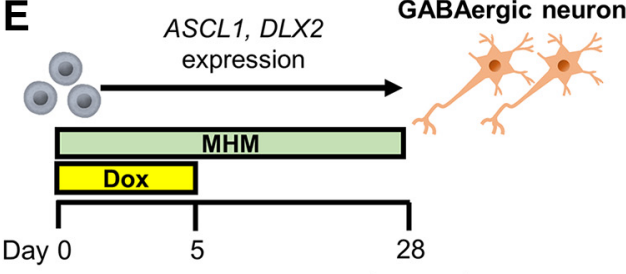

F
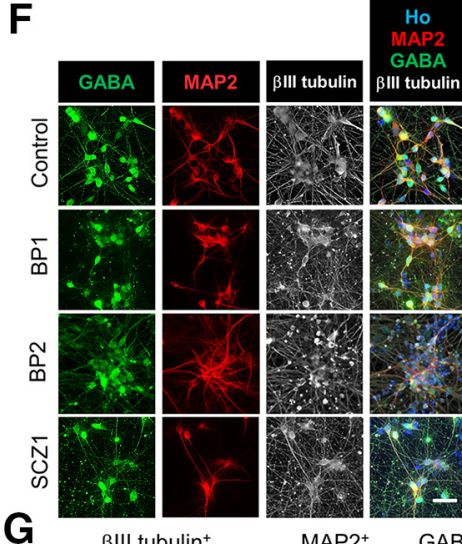$$
\text { (Bil tubuin }
$$

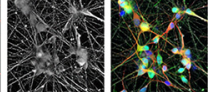

G

BIII tubulin ${ }^{+}$

$/ \mathrm{Ho}^{+}$
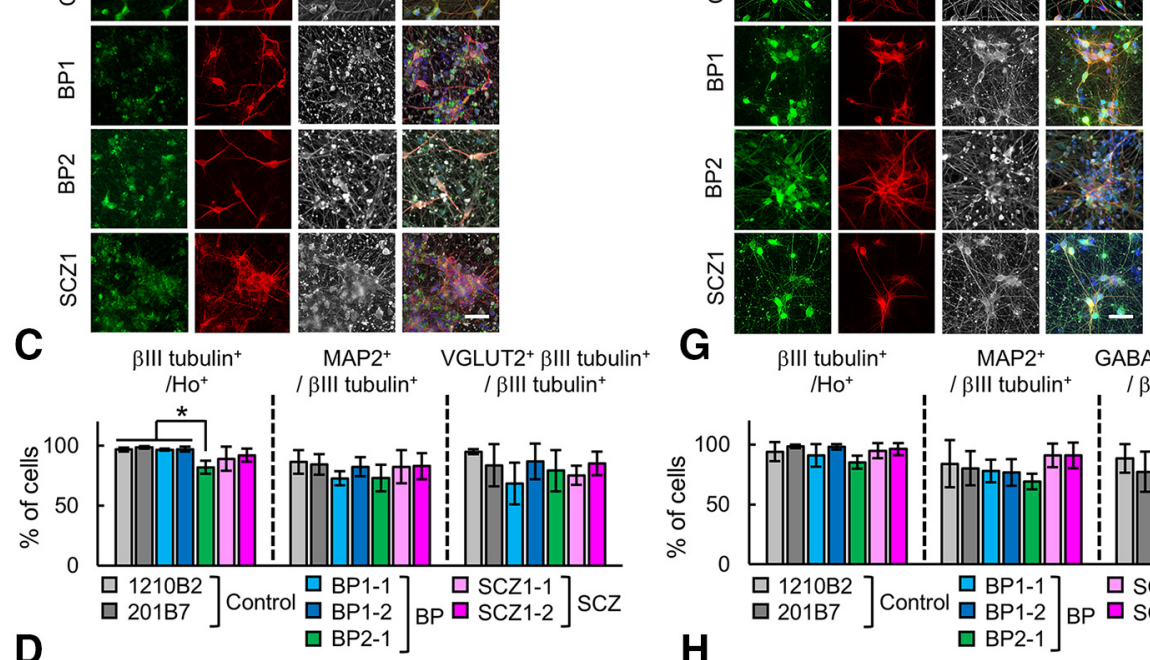

D

PCDH15

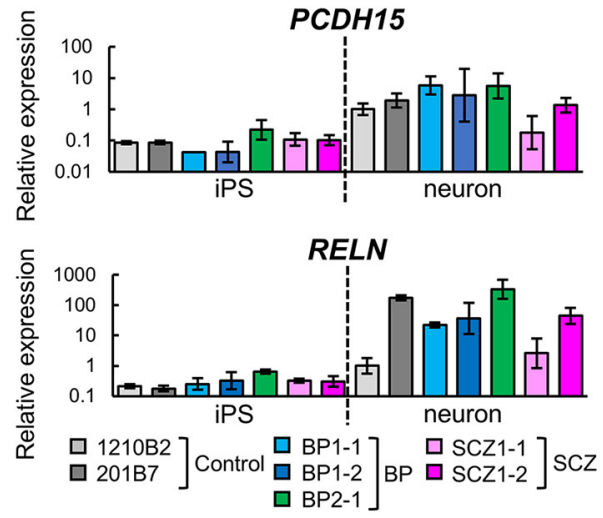

H
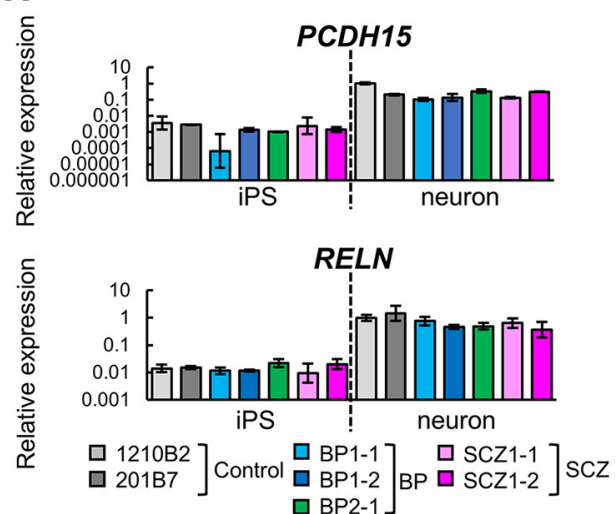

Figure 3. Neuron differentiation by transcription factor overexpression. $\boldsymbol{A}$, Overview of the protocol for differentiation into glutamatergic neurons. B, Immunocytochemical analysis of neuronal markers (VGluT2, MAP2, and $\beta$ III tubulin). Scale bar, $40 \mu \mathrm{m}$. $\boldsymbol{C}$, Ratio of positive cells for each marker; $\beta$ III tubulin ${ }^{+}$cells/all cells ( $\beta$ III tubulin ${ }^{+} / \mathrm{Ho}^{+}$), MAP2 ${ }^{+}$cells $/ \beta$ III tubulin ${ }^{+}$cells $\left(\mathrm{MAP2}^{+} / \beta\right.$ IIII-tubulin ${ }^{+}$), and VGluT2 and $\beta$ III tubulin double ${ }^{+}$cells/ $\beta$ III tubulin ${ }^{+}$cells $\left(\mathrm{VGLUT2}^{+} \beta\right.$ III tubulin ${ }^{+} / \beta$ III tubulin $\left.{ }^{+}\right) .(n=3-6$ independent experiments; mean \pm SD; $* p<0.05$; Tukey's test, the population of $\beta$ III tubulin ${ }^{+}$cells in BP2-1-derived neurons was significantly lower than those in 1210B2-, 201B7-, BP1-1-, and BP1-2-derived neurons). $\boldsymbol{D}$, Relative gene expression levels of PCDH15 (primer set1) and RELN in NEUROG2-transduced iPSCs and induced neurons ( $n=3$ independent experiments; mean \pm SD; Dunnett's test among iPSCs and among neurons, no significant differences were observed). Values were normalized to that for 1210B2-derived neurons, which was considered to be 1.0. Some iPSC samples, in which PCDH15 expression was under the detection limit, were removed from the analysis. Specifically, two samples of BP1-1, and one sample of 1210B2, 201B7, BP2-1, and SCZ1-1 were excluded from the analysis. $\boldsymbol{E}$, Overview of the protocol for differentiation into GABAergic neurons. $\boldsymbol{F}$, Immunocytochemical analysis of neuronal markers (MAP2, GABA, and $\beta$ III tubulin). Scale bar, $40 \mu \mathrm{m}$. $\boldsymbol{G}$, Ratio of positive cells for each marker; $\beta$ III tubulin ${ }^{+}$cells/all cells $\left(\beta\right.$ III tubulin $\left.{ }^{+} / \mathrm{Ho}^{+}\right)$, MAP2 ${ }^{+}$cells $/ \beta$ III tubulin ${ }^{+}$cells $\left(\mathrm{MAP2}^{+} / \beta\right.$ III tubulin ${ }^{+}$), and GABA and $\beta$ III-tubulin double-positive cells/ $\beta$ III tubulin ${ }^{+}$cells $\left(\mathrm{GABA}^{+} \beta\right.$ III tubulin ${ }^{+} / \beta$ III tubulin $\left.{ }^{+}\right) .(n=3-6$ independent experiments; mean $\pm \mathrm{SD}$; Tukey's test; no significant differences were observed). $\boldsymbol{H}$, Relative gene expression levels of PCDH15 and RELN in ASCL1- and $D L X 2$-transduced iPSCs and induced neurons. $(n=3$ independent experiments; mean \pm SD; Dunnett's test among iPSCs and among neurons; no significant differences were observed). Values were normalized to that for 1210B2-derived neurons, which was considered to be 1.0. Some iPSC samples, in which PCDH15 expression was under the detection limit, were removed from the analysis. Specifically, each one sample of $1210 \mathrm{~B} 2$ and BP2-1 was excluded from the analysis. 
A

\section{Glutamatergic neuron}

Component-2

B
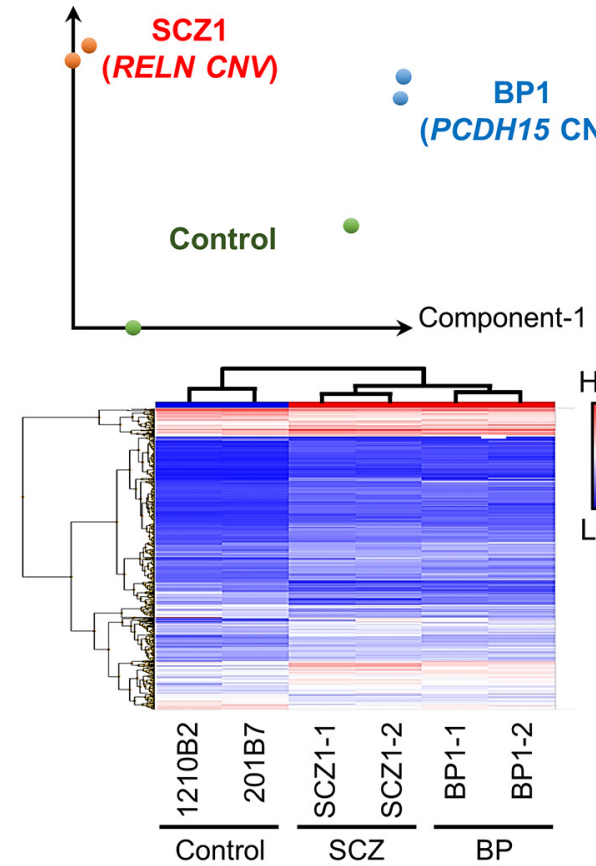

C

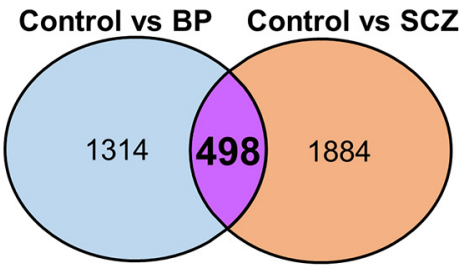

D

Gene Ontology

\begin{tabular}{|l|r|}
\hline \multicolumn{1}{|c|}{ Term } & \multicolumn{1}{c|}{ P Value } \\
\hline cell adhesion & $2.81 \mathrm{E}-05$ \\
\hline chemical synaptic transmission & 0.0106 \\
\hline $\begin{array}{l}\text { regulation of N-methyl-D-aspartate selective } \\
\text { glutamate receptor activity }\end{array}$ & 0.0463 \\
\hline
\end{tabular}

Pathway

\begin{tabular}{|l|c|}
\hline \multicolumn{1}{|c|}{ Term } & P Value \\
\hline Focal adhesion & 0.00334 \\
\hline
\end{tabular}

$\mathbf{E}$

\section{GABAergic neuron}

Component-2

High

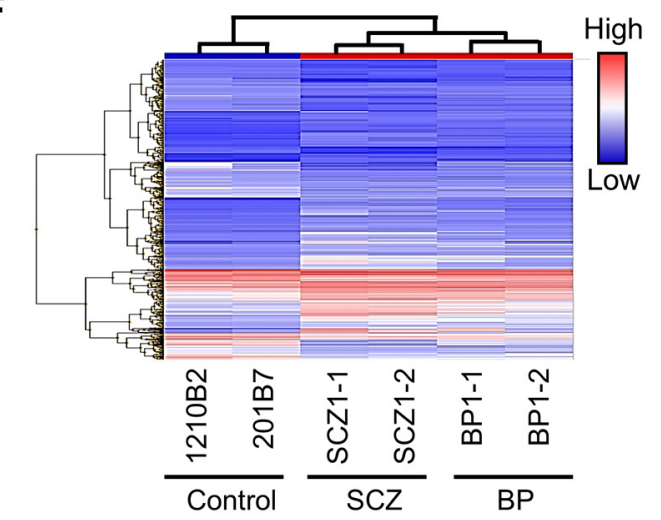

G

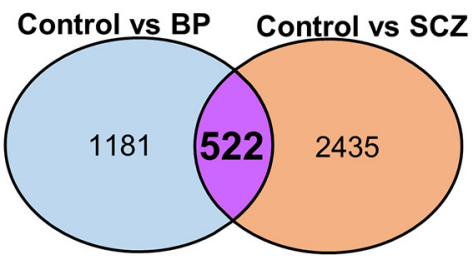

H

Gene Ontology

\begin{tabular}{|l|r|}
\hline \multicolumn{1}{|c|}{ Term } & \multicolumn{1}{c|}{ P Value } \\
\hline focal adhesion & $4.74 \mathrm{E}-04$ \\
\hline collagen binding & 0.00452 \\
\hline chemical synaptic transmission & 0.0112 \\
\hline positive regulation of synapse assembly & 0.0234 \\
\hline laminin binding & 0.0261 \\
\hline cell adhesion & 0.0351 \\
\hline
\end{tabular}

Pathway

\begin{tabular}{|l|r|}
\hline \multicolumn{1}{|c|}{ Term } & \multicolumn{1}{|c|}{ P Value } \\
\hline Focal adhesion & $6.07 \mathrm{E}-08$ \\
\hline ECM-receptor interaction & $7.23 \mathrm{E}-04$ \\
\hline MAPK signaling pathway & 0.0128 \\
\hline Serotonergic synapse & 0.0129 \\
\hline Glutamatergic synapse & 0.0150 \\
\hline Cell adhesion molecules (CAMs) & 0.0187 \\
\hline GABAergic synapse & 0.0324 \\
\hline Morphine addiction & 0.0431 \\
\hline
\end{tabular}

Figure 4. Comparison of the global gene expression profiles. $\boldsymbol{A}$, PCA of the gene expression data of glutamatergic neurons. $\boldsymbol{B}$, Hierarchical clustering analysis of DEGs in glutamatergic neurons. $\boldsymbol{C}$, Venn diagram of DEGs of BP or SCZ glutamatergic neurons compared with control neurons (fold change, >2.0). A total of 498 genes were common between the two groups compared. $\boldsymbol{D}$, Featured GO and pathway terms for the 498 common DEGs among the control vs BP and control vs SCZ. Adhesion- and neuron-associated terms were extracted. $\boldsymbol{E}$, PCA plot of the gene expression data of GABAergic neurons. Green, control (1210B2, 201B7); blue, BP; red, SCZ. $\boldsymbol{F}$, Hierarchical clustering analysis of DEGs in GABAergic neurons. $\boldsymbol{G}$, Venn diagram of DEGs of BP or SCZ GABAergic neurons in comparison with control neurons (fold change, >2.0). A total of 522 genes were common among the two comparisons. $\boldsymbol{H}$, Featured GO and pathway terms for 522 common DEGs among the control vs BP and control vs SCZ. Adhesionand neuron-associated terms were extracted. 
A

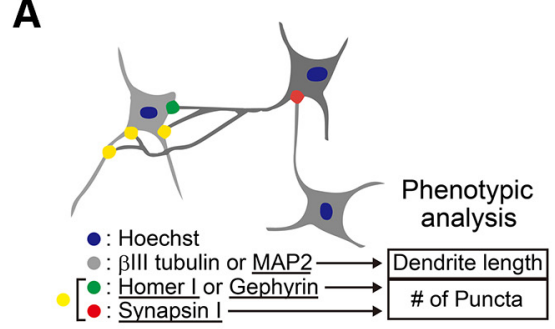

B
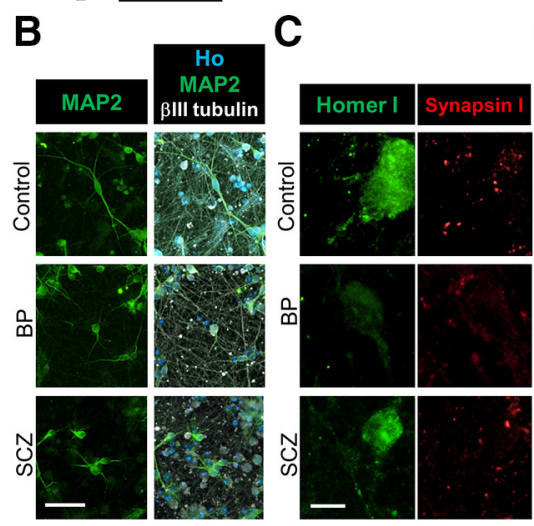

D

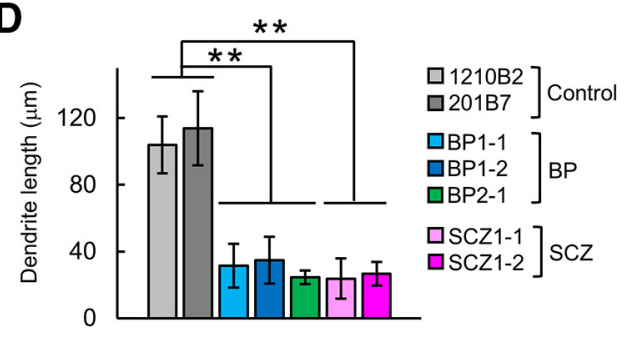

E
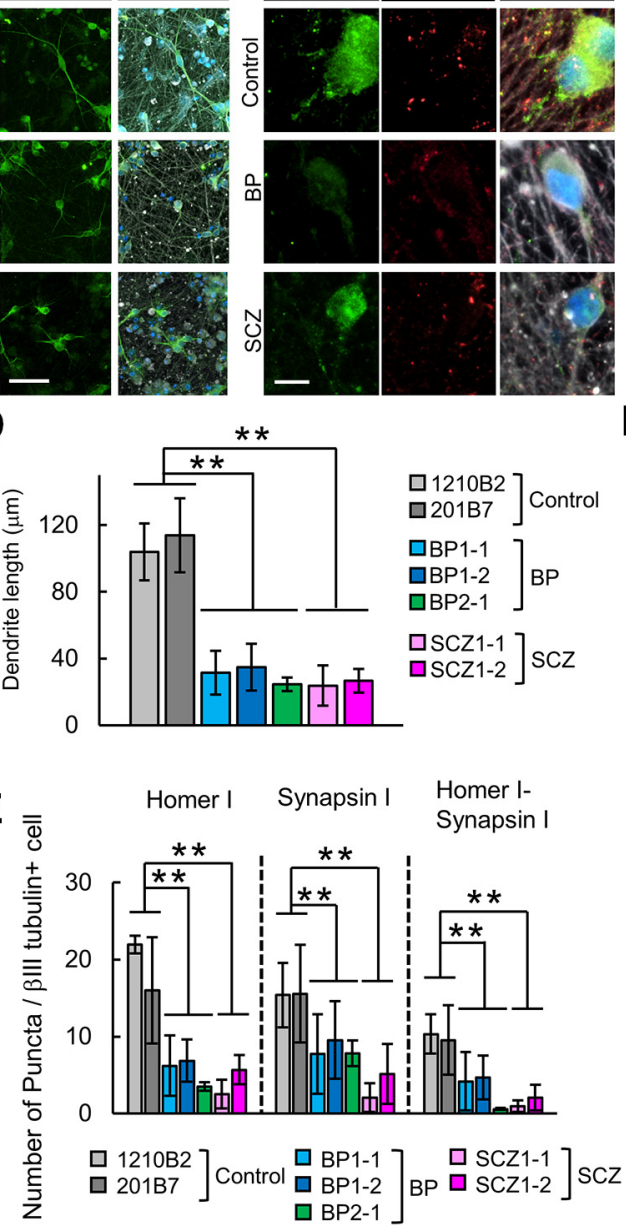

Glutamatergic GABAergic

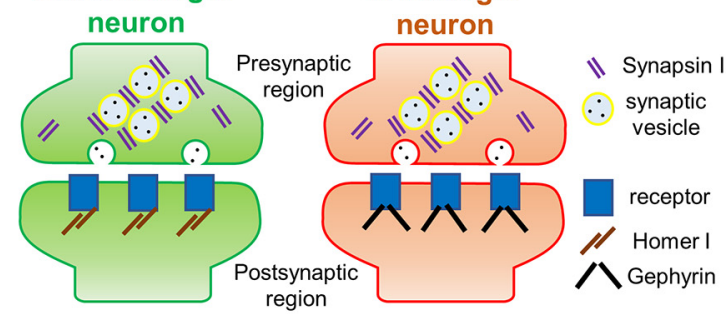

$F$
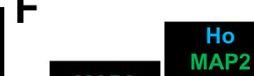

MAP2
IIII tubulin

G
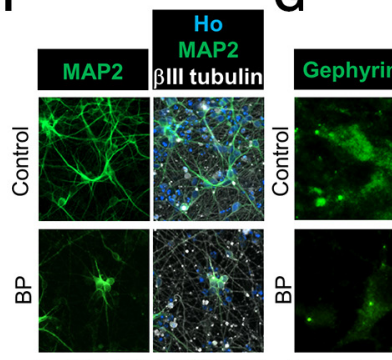

symanein
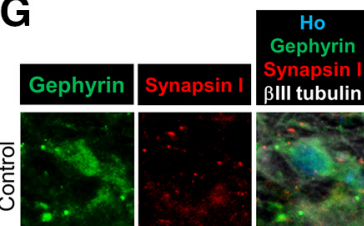

BIII tubulin
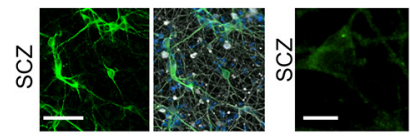

H
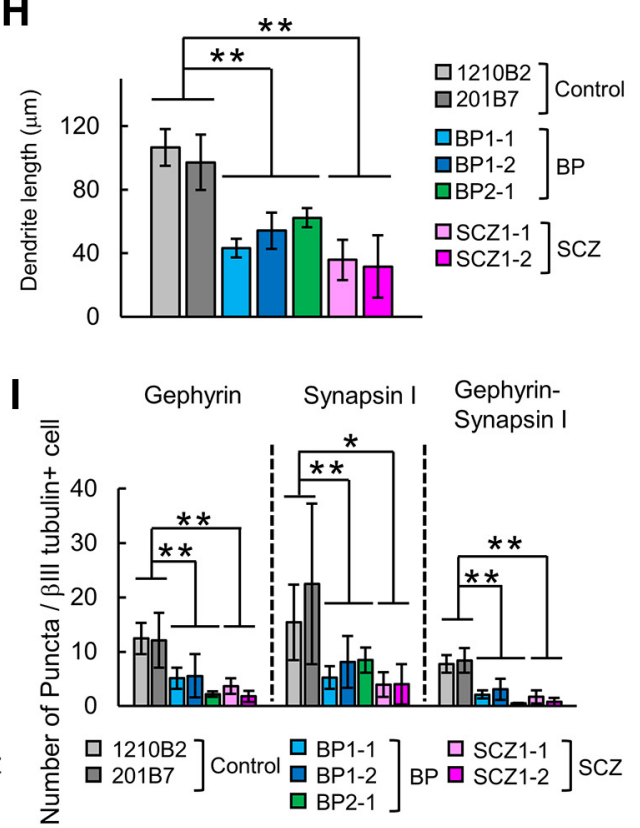

Figure 5. Neurons induced from patient-derived iPSCs exhibit abnormal phenotypes of dendrite length and synapse formation. $\boldsymbol{A}$, Schematic diagram of the protocol for phenotypic analysis of dendrite lengths and number of synaptic markers of the neurons. $\boldsymbol{B}, \boldsymbol{C}$, Representative images of immunocytochemical analysis of a dendrite marker (MAP2; scale bar, $60 \mu \mathrm{m}$; $\boldsymbol{B}$ ) and synaptic markers (Homer I, Synapsin I; scale bar, $10 \mu \mathrm{m} ; \boldsymbol{C}$ ) in glutamatergic neurons. D, Quantitative analysis of dendrite length in glutamatergic neurons ( $n=3-6$ independent experiments; mean $\pm \mathrm{SD} ; * * p<0.01$; Dunnett's test). E, Quantitative analysis of the number of synaptic marker puncta in glutamatergic neurons $(n=3-6$ independent experiments; mean \pm SD; $* p<0.05, * * p<0.01$; Dunnett's test). Homer I puncta, Synapsin I puncta and Homer-Synapsin I colocalized puncta on $\beta$ III-tubulin ${ }^{+}$cells were counted. $\boldsymbol{F}$, $\mathbf{G}$, Representative images of immunocytochemical analysis of a dendrite marker (MAP2; scale bar, $60 \mu \mathrm{m}$; $\boldsymbol{F}$ ) and synaptic markers (Gephyrin, Synapsin I; scale bar, $10 \mu \mathrm{m}$; G) in GABAergic neurons. $\boldsymbol{H}$, Quantitative analysis of dendrite length in GABAergic neurons ( $n=3-6$ independent experiments; mean \pm SD; $* * p<0.01$, Dunnett's test). I, Quantitative analysis of the number of synaptic marker puncta in glutamatergic neurons $(n=3-6$ independent experiments; mean $\pm \mathrm{SD} ; * p<0.05, * * p<0.01$, Dunnett's test). Gephyrin

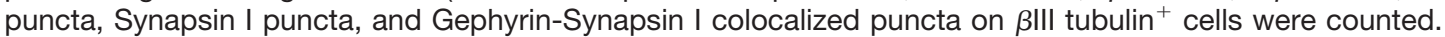

Cas9 system. To generate $\mathrm{PCDH} 15$-deleted iPSCs, sgRNAs were constructed in exon 9 (Fig. 6A). According to the results of the T7E1 assay (see Materials and Methods), sgRNA\#3 showed the strongest cleavage activity among the five sgRNA candidates (Fig. $6 B$ ). We obtained an isogenic line with the homozygous $P C D H 15$ deletion (PCDH15del) from healthy control NC1032-1-2 (Control 1; Fig. $6 C)$. PCDH15del mutant iPSCs showed the capacity 
A
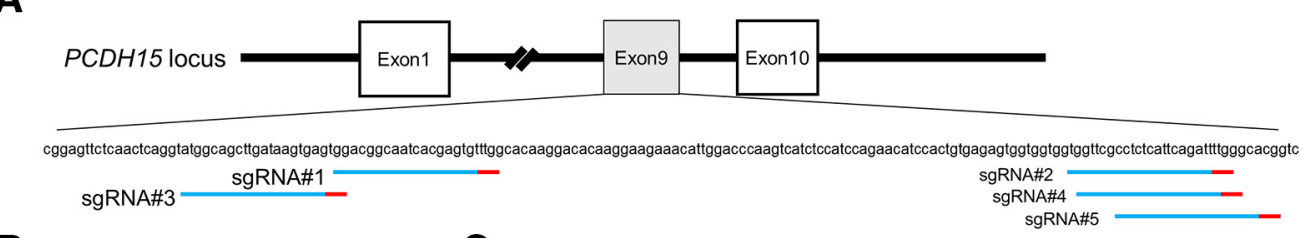

B C

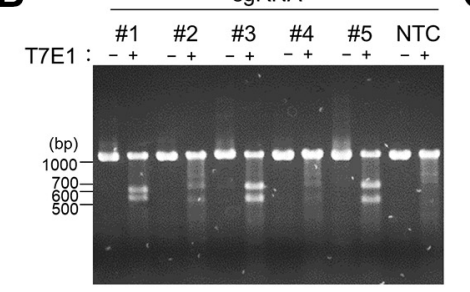

D

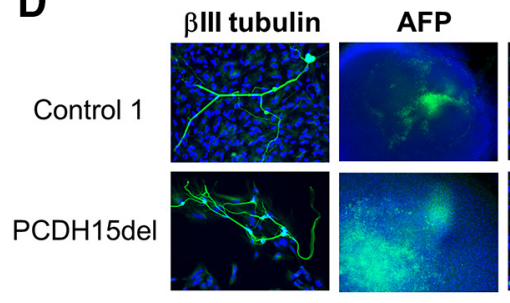

$\mathbf{F}$

\begin{tabular}{|c|c|c|c|}
\hline & Indel region & Genotype & Ref. \\
\hline RELNdel & $\begin{array}{c}\text { Exon } 52 \\
(-14 \mathrm{bp} /-11 \mathrm{bp})\end{array}$ & $-/-$ & $\begin{array}{c}\text { Arioka et al. } \\
(2018)\end{array}$ \\
\hline
\end{tabular}

\begin{tabular}{|c|l|c|c|}
\hline & \multicolumn{1}{|c|}{$\begin{array}{c}\text { Forward strand sequence 5'->3' } \\
\text { (Ref. NM_001142763) }\end{array}$} & Indel & Genotype \\
\hline Ref. & tcaactcaggtatggcagcttgataagtgagtggacggcaatcacgagtgt & & \\
\hline PCDH15del & $\begin{array}{l}\text { tcaactcaggtatggcagcttgata----agtggacggcaatcacgagtgt } \\
\text { tcaactcaggtatggcagcttg--------agtggacggcaatcacgagtgt }\end{array}$ & $\begin{array}{l}-4 \mathrm{bp} \\
-7 \mathrm{bp}\end{array}$ & $-/-$ \\
\hline
\end{tabular}

aSMA

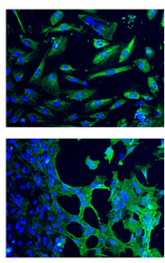

G

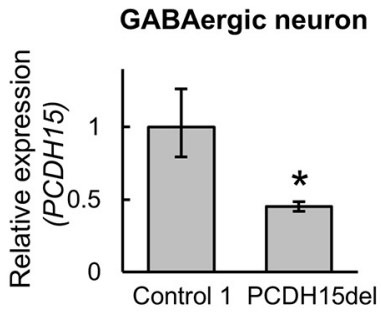

E

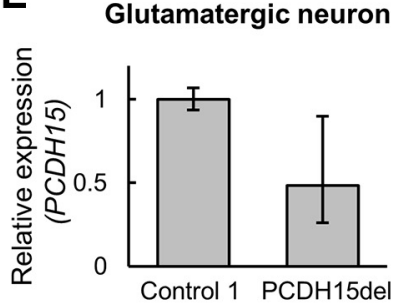

Glutamatergic neuron

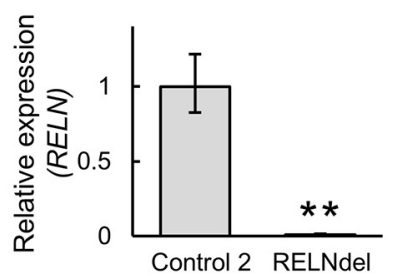

GABAergic neuron

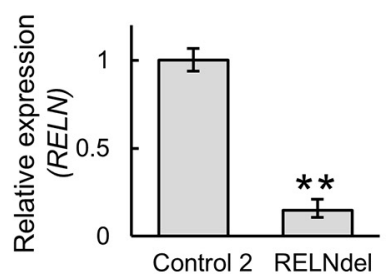

Figure 6. Generation of isogenic $P C D H 15$ deletion iPSCs by targeted genome editing. $\boldsymbol{A}$, The target sites of CRISPR-sgRNAs in exon 9 of the PCDH15 gene (NM_001142763). Red bars represent PAM (protospacer adjacent motif) sequences. B, Analysis of CRISPR-sgRNA activity by the T7E1 assay using HEK293FT. NTC, No transfection. Among the constructed sgRNAs, sgRNA\#3 showed the strongest cleavage activity. $\boldsymbol{C}$, Indel pattern of the isogenic line using CRISPR-sgRNA\#3. Blue letters represent stop codon. $\boldsymbol{D}$, Representative images of immunocytochemical analysis for in vitro three-germ layer differentiation. Blue indicates Ho and green indicates the pluripotent marker ( $\beta$ III-tubulin, $\alpha$ SMA, and AFP). Scale bar, $100 \mu \mathrm{m}$. $\boldsymbol{E}$, Relative gene expression levels of $P C D H 15$ (primer set2) in glutamatergic or GABAergic neurons on day 28 ( $n=3$ independent experiments; mean $\pm \mathrm{SD} ; * p<0.05$, Student's $t$ test). $\boldsymbol{F}$, Information of isogenic $R E L N$-deleted iPSCs generated in the previous study (Arioka et al., 2018). G, Relative gene expression levels of RELN in induced glutamatergic or GABAergic neurons on day 28 ( $n=3$ independent experiments; mean $\pm \mathrm{SD}$; **p $<0.01$, Student's $t$ test).

to differentiate into three germ layers as well as Control 1 (Fig. 6D). Then, we analyzed the expression level of $P C D H 15$ by qRT-PCR using the primer set targeting the deleted region. The mRNA level of $P C D H 15$ was decreased by about 50\% in PCDH15del-induced neurons (PCDH15del neurons) when normalized to Control 1-induced neurons (Fig. 6E). We also prepared an isogenic line with the homozygous RELN deletion (RELNdel) that was established from 201B7 (Control 2) in a previous study (Arioka et al., 2018; Fig. 6F). Remarkably, the expression level of RELN in RELNdel-induced neurons (RELNdel neurons) was much lower than that in Control 2-induced neurons (Fig. 6G).

\section{Dendritic and synaptic characterization of isogenic PCDH15- or RELN-deleted neurons}

To investigate whether our isogenic gene-edited iPSCderived neurons recapitulate patient iPSC-derived neu- rons, we performed phenotypic analyses focusing on their dendrite length and synapse formation using the same method as performed in Figure 5. Both glutamatergic and GABAergic neurons were efficiently induced from PCDH15del and RELNdel (Fig. 7A,B,E,F). While some differentiation characteristics were confirmed, $>60 \%$ of cell populations constantly differentiated into our target neurons in all cell lines we tested (Fig. 7B,F).

Regarding glutamatergic neurons, $\mathrm{MAP}^{+}$dendrites of PCDH15del neurons were significantly shorter than those of Control 1 neurons, while RELNdel neurons tended to form shorter dendrites than Control 2 neurons, although the difference was not statistically significant $(p=0.063$; Fig. 7C). Unlike patient-derived neurons, the number of Homer I puncta was increased in both PCDH15del neurons and RELNdel neurons compared with Control 1 or 2 
A

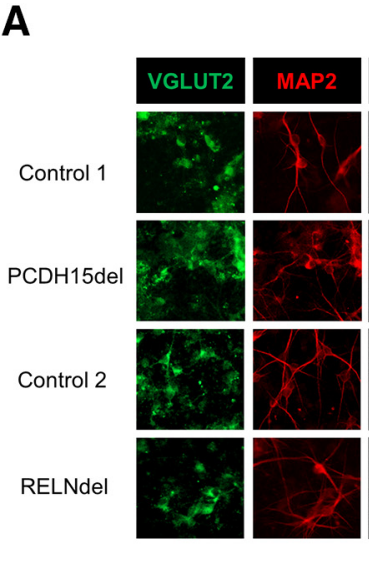

C

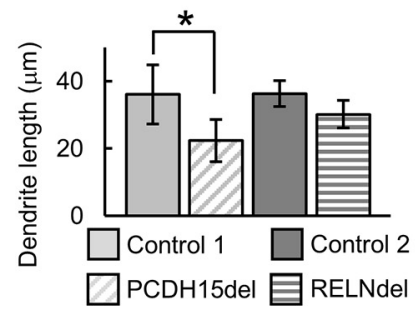

E

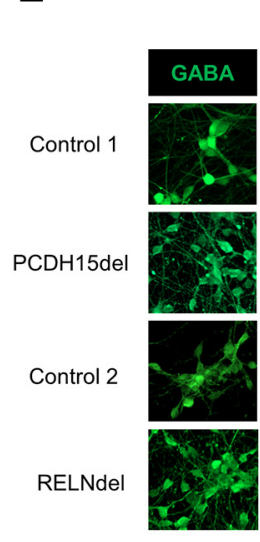

G

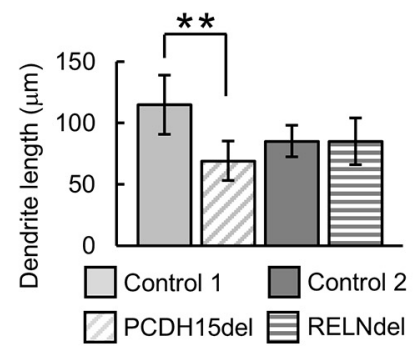

Ho

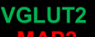

MAP2
$\beta$ III tubulin
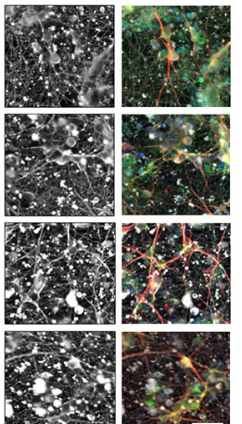

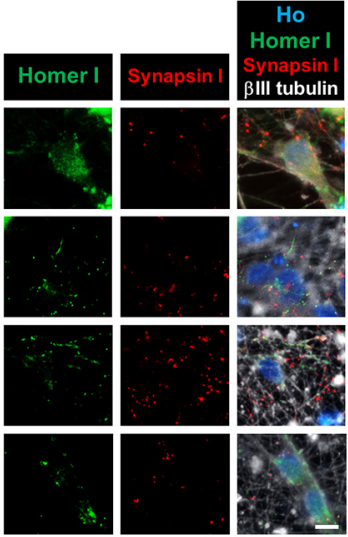

B

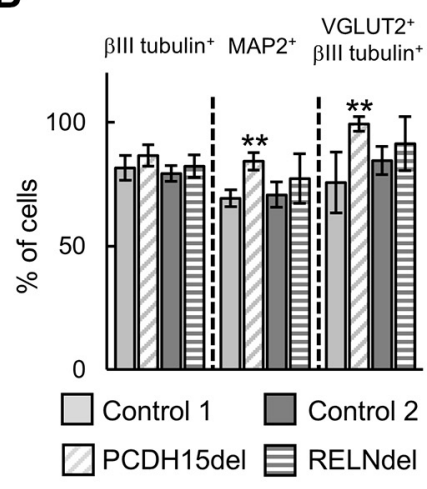

D $\overline{\overline{\mathrm{g}}}$

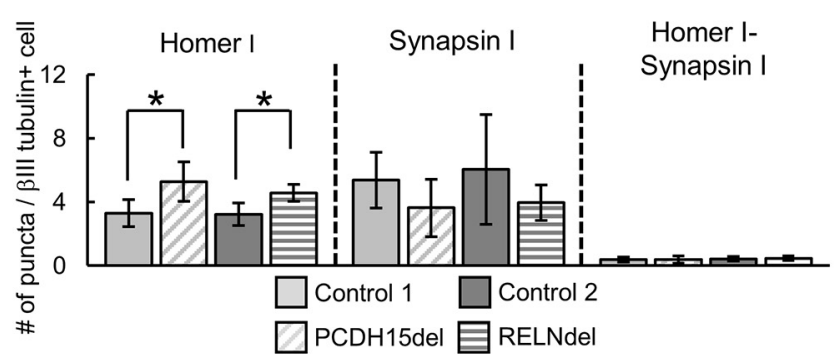

$\mathbf{F}$

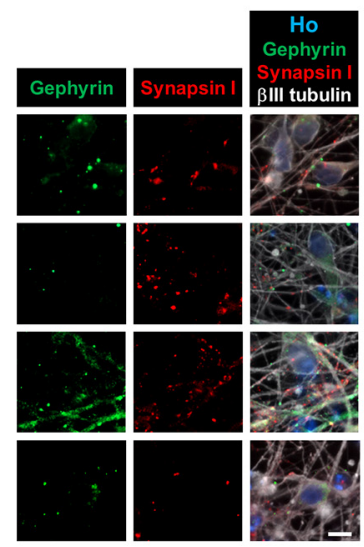

Gephyrin

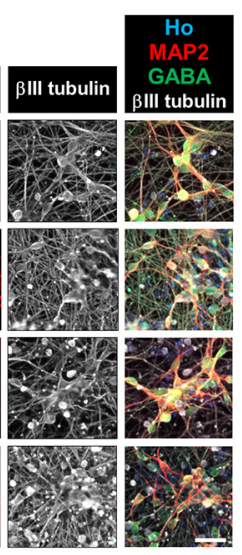

H

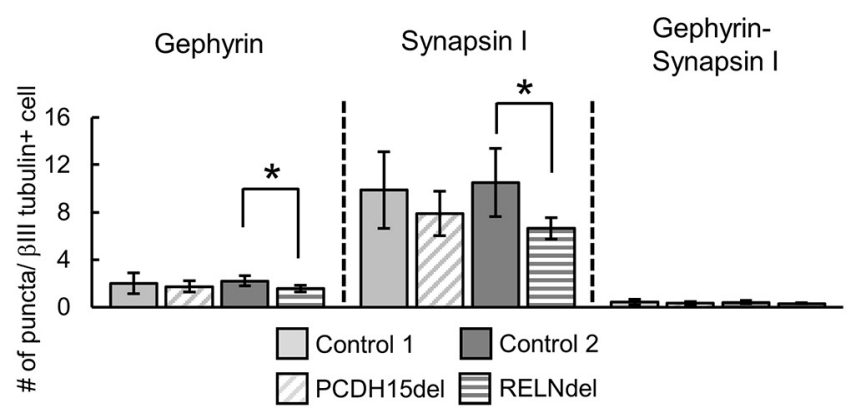

Figure 7. Isogenic $P C D H 15$ or RELN deleted neurons showed partial phenotypes of dendrite and synapse formation. $\boldsymbol{A}$, Representative images of immunocytochemical analysis of neuronal markers (scale bar, $40 \mu \mathrm{m}$ ) and synaptic markers (scale bar, $10 \mu \mathrm{m})$ in glutamatergic neurons. $\boldsymbol{B}$, Ratio of positive cells for each marker; $\beta$ III tubulin ${ }^{+}$cells/all cells $\left(\beta\right.$ III tubulin $\left.{ }^{+}\right)$, MAP2 $^{+}$cells/ $\beta$ III tubulin ${ }^{+}$ cells $\left(\mathrm{MAP}^{+}{ }^{+}\right.$), and VGLUT2 and $\beta$ III tubulin double-positive cells/ $\beta$ III tubulin ${ }^{+}$cells (VGluT2 ${ }^{+} \beta$ III tubulin $\left.{ }^{+}\right) .(n=4-6$ independent experiments; mean $\pm \mathrm{SD} ; * * p<0.01$, Student's $t$ test between each pair of control and isogenic lines). $\boldsymbol{C}$, Quantitative analysis of dendrite length in glutamatergic neurons $(n=4-6$ independent experiments; mean $\pm \mathrm{SD} ; *<0.05$, Student's $t$ test). $\boldsymbol{D}$, Quantitative analysis of the number of synaptic marker puncta in glutamatergic neurons $(n=3-6$ independent experiments; mean \pm SD; $* p<$ 0.05 , Student's $t$ test). $\boldsymbol{E}$, Representative images of immunocytochemical analysis of neuronal markers (scale bar, $40 \mu \mathrm{m})$ and synaptic markers (scale bar, $10 \mu \mathrm{m}$ ) in GABAergic neurons. $\boldsymbol{F}$, Ratio of positive cells for each marker; $\beta$ III tubulin ${ }^{+}$, MAP2 ${ }^{+}$, and GABA and $\beta$ III tubulin double-positive cells/ $\beta$ III tubulin ${ }^{+}$neuronal cells $\left(\mathrm{GABA}^{+} \beta \mathrm{III}\right.$ tubulin $\left.{ }^{+}\right)$. $(n=4-6$ independent experiments; mean $\pm \mathrm{SD} ; * p<$ 0.05 , Student's $t$ test between Control 1 and PCDH15del or between Control 2 and RELNdel). G, Quantitative analysis of dendrite 
continued

length in GABAergic neurons ( $n=4-6$ independent experiments; mean $\pm \mathrm{SD} ; * * p<0.01$, Student's $t$ test). $\boldsymbol{H}$, Quantitative analysis of the number of synaptic marker puncta in GABAergic neurons $(n=4-6$ independent experiments; mean \pm SD; $* p<0.05$, Student's $t$ test).

neurons (Fig. 7D). The number of Synapsin I puncta and colocalized puncta of Homer I and Synapsin I tended to be lower in isogenic lines, although the changes were not significant (Fig. 7D). Regarding GABAergic neurons, MAP2 ${ }^{+}$ dendrite shortening was observed only in PCDH15del neurons (Fig. 7G), while both Gephyrin and Synapsin I puncta were significantly decreased only in RELNdel neurons (Fig. $7 H$ ). The number of colocalized puncta was not significantly different in either isogenic line (Fig. $7 H$ ). Based on these findings, isogenic gene-edited lines partially recapitulated the structural phenotypes observed in patient-derived lines.

\section{Assessment of neuronal function of patient-derived and isogenic iPSCs-derived neurons}

We showed that patient-derived neurons or isogenic gene-edited neurons displayed structural phenotypes. However, it remains unknown whether these neurons show differences in functional activity. Thus, we investigated their neuronal function by assaying spontaneous neuronal activity. To clearly assess neuronal activity, we evaluated the effect of BrainPhys medium, which was developed to support neurophysiological activity (Bardy et al., 2015) on neuronal phenotypes we detected (Fig. $8 A$ ). Even by culturing with BrainPhys, BP and SCZ neurons showed the recapitulated phenotypes of dendrite shortening and decreased synapse number and for both glutamatergic and GABAergic neurons (Fig. 8B). Based on these results, we used BrainPhys as the neuron culture media for functional analysis.

For MEA analysis, we induced neurons from iPSCs directly on the MEA plates at a high density (Fig. $8 C$ ). Spontaneous activity was detected by 16 electrodes per well in the MEA plate, and the activities of neurons were recorded at each electrode (Fig. $8 D$ ). In glutamatergic neurons, active electrodes were stably detected on day 28 after induction, while few active electrodes appeared in GABAergic neurons on day 28 (data not shown). In spike frequency of glutamatergic neurons on day 28 and day 42 , there were no significant differences in spike frequency among control, BP, and SCZ groups, although the time-dependent increase in spike frequencies of each group (Fig. 8E). Isogenic PCDH15-deleted or RELNdeleted neurons also showed no significant differences compared with Control 1 or Control 2 both on day 28 and day 42 , except for the time-dependent increase in spike frequencies (Fig. 8F). These results indicate that spontaneous neuronal activity was maintained at a comparable level among glutamatergic neurons whether they were control neurons, patient-derived neurons, or isogenic neurons.

Next, we investigated receptor reactivity by treatment with a glutamate receptor antagonist (AMPA receptor antagonist CNQX and NMDA receptor antagonist AP-5) or GABA receptor agonist (GABA). By using induced glutamatergic neurons, we measured changes in the total number of spikes per well before and after treatment. We found that the spike number was significantly decreased both in BP and SCZ neurons after CNQX treatment, but not after AP-5 treatment compared with Control neurons (Fig. 8G). Similarly, GABA treatment resulted in a significant decrease in spike number in SCZ neurons compared with Control neurons (Fig. 8G). These results suggest that BP and SCZ neurons have higher sensitivities in AMPA receptor and GABA receptor stimulation, which might lead to the maintenance of spontaneous activity of neurons.

In GABAergic neurons, 6 weeks of differentiation enabled neurons to have active spikes in most patientderived and isogenic lines. However, some cell lines did not show sufficient neuronal activity to be analyzed (data not shown). Then, we used a calcium imaging system to detect the GABAergic neuron activity with higher sensitivity. We used $1210 \mathrm{~B} 2$ as a healthy control for comparison with patient-derived lines. We recorded spontaneous calcium spikes from GABAergic neurons on day 28 and focused on the following parameters: $\Delta F \max$ and spike number (Fig. $8 \mathrm{H}$; see also Materials and Methods). There were no significant differences both in $\Delta F \max$ and spike frequency among control- and patient-derived lines (Fig. 8). Isogenic neurons also showed no significant differences in these parameters compared with controls (Fig. $8 J)$. These results of calcium imaging thus suggest that the spontaneous activity of GABAergic neurons is comparable among control, patient-derived, and isogenic neurons, indicating some compensatory mechanism for structural abnormalities.

\section{Discussion}

It is challenging to elucidate the molecular mechanisms and general pathologies of BP and SCZ for the following two reasons: the genetic background complexity of these disorders and the difficulty of pathological recapitulation. However, neurons induced from patient-derived iPSCs can overcome these problems. In particular, the use of iPSCs derived from patients with disease-associated CNVs is a promising strategy (Flaherty et al., 2017; Rutkowski et al., 2017). In the present study, we focused on the following two CNVs: the heterozygous deletion of $P C D H 15$ and of RELN. We used newly generated iPSCs derived from BP patients with $\mathrm{PCDH} 15$ deletion and differentiated the BP-iPSCs (PCDH15-deleted) and SCZiPSCs (RELN-deleted) into neurons efficiently. We identified several neuronal abnormalities in neurons induced from patient-derived iPSCs.

In this study, we used the following two types of methods for neural differentiation: induction by chemical treatment or overexpression of transcription factors. Neurons induced from patient-derived iPSCs using the chemical treatment method exhibited abnormal phenotypes of neurite extension in the early differentiation stage. Although 
A

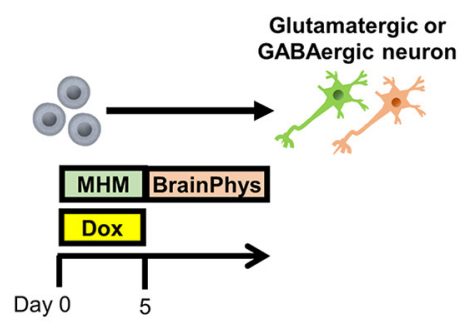

C

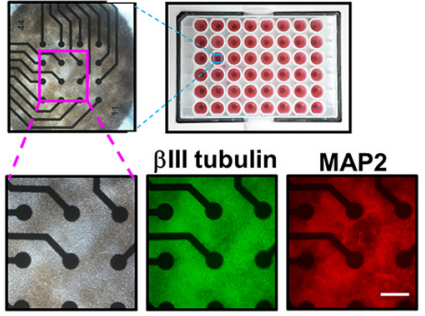

E

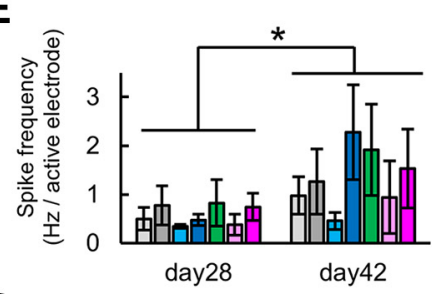

G
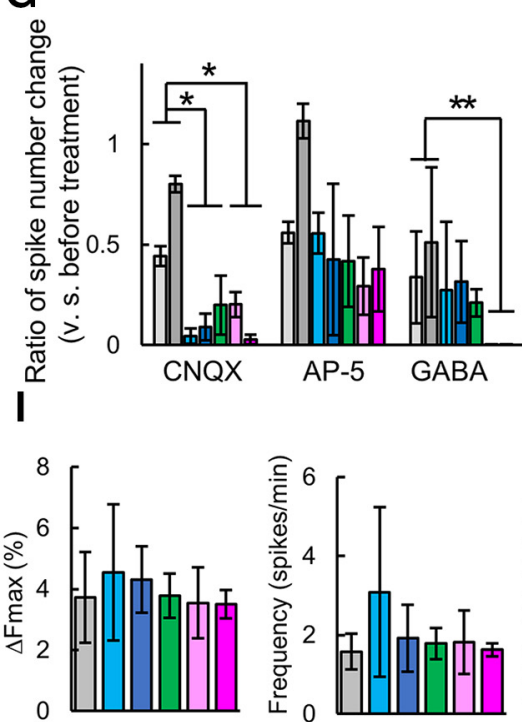

B

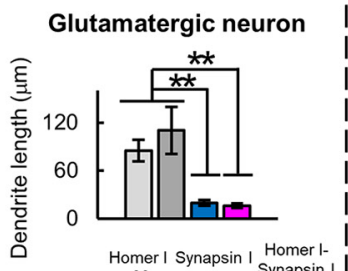

GABAergic neuron

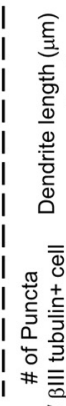

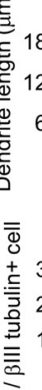

D

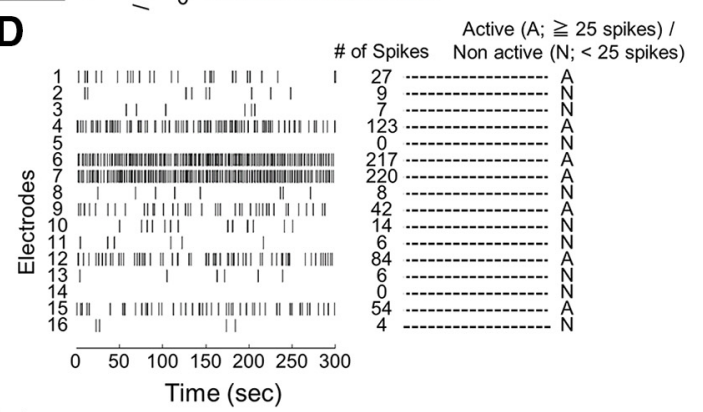

F

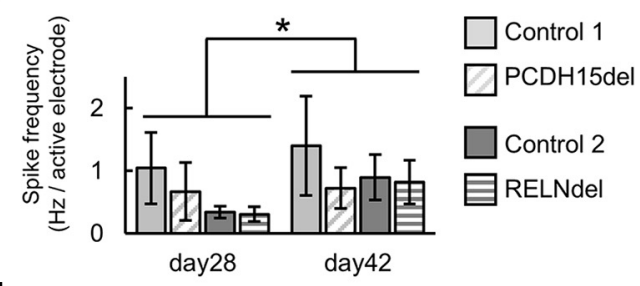

H

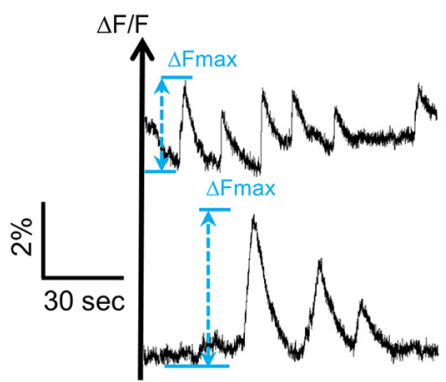

J

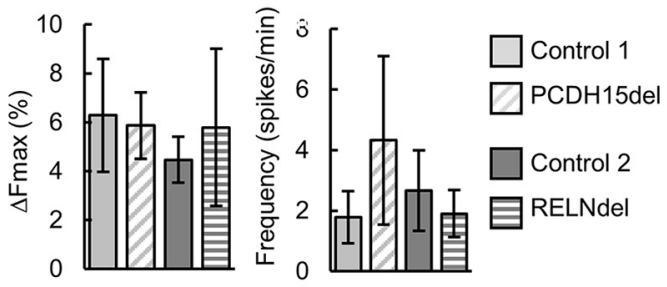

Figure 8. Spontaneous activity of neurons induced from patient-derived or isogenic iPSCs. A, Overview of the protocol for neuronal differentiation for functional analysis. B, Quantitative analysis of dendrite length and synaptic markers puncta in neurons cultured in BrainPhys for differentiation on day 28 ( $n=3-4$ independent experiments; mean \pm SD; $* * p<0.01$, Dunnett's test among control, BP, and SCZ neurons; BP: BP1-2, SCZ: SCZ1-2). C, Overview of MEA plate and representative images of neurons induced from iPSCs on the 48-well MEA plates. Bright-field image and immunocytochemical images of neuron markers. Scale bar, $200 \mu \mathrm{m}$. $\boldsymbol{D}$, Representative image of raster plot and definition of active electrodes. $\boldsymbol{E}$, Spike frequency of control or patient-derived glutamatergic neurons on day 28 and day 42 ( $n=4-6$ independent experiments; mean \pm SD; Dunnett's test among Control, BP, and SCZ neurons, no significant differences were observed; paired $t$ test between day 28 and day $42, * p<0.05)$. $\boldsymbol{F}$, Spike frequency of isogenic iPSC-derived glutamatergic neurons $(n=3-4$ independent experiments; mean \pm SD; Dunnett's test among Control, BP, and SCZ neurons, no significant differences were observed; paired $t$ test between day 28 and day $42, * p<0.05)$. G, Relative change in the total number of spikes after drug treatment in glutamatergic neurons on day 42 ( $n=3$ independent experiments; mean \pm SD; $* p<$ 
continued

$0.05, * * p<0.01$, Dunnett's test). $\boldsymbol{H}$, Representative image of calcium spikes and display of parameters $(\Delta F$ max and calcium spike numbers). $\boldsymbol{I}, \Delta$ Fmax and calcium spike frequency in control or patient-derived GABAergic neurons $(n=3-6$ independent experiments; mean \pm SD; Dunnett's test among each line, no significant differences were observed). $\boldsymbol{J}, \Delta F$ max and calcium spike frequency in control or patient-derived GABAergic neurons $(n=4-6$ independent experiments; mean \pm SD; Student's $t$ test, no significant differences were observed).

these phenotypes may support the neurodevelopmental hypothesis for BP and SCZ (O'Shea and Mclnnis, 2016; Owen and O'Donovan, 2017), this differentiation method is not suited for the analysis of adult and specific pathologies for medical treatment. On the other hand, we showed that transcription factor overexpression is suitable for the preparation of specific types of mature neurons and analysis of the phenotypes of clinical pathologies. NEUROG2 overexpression induced glutamatergic neurons, and ASCL1 and DLX2 co-overexpression induced GABAergic neurons, from iPSCs efficiently, which enabled analysis of the phenotype of each type of neuron. In addition, this type of method is expected to be applicable for electrophysiological analysis of specific neurons or functional analysis of neural networks by coculturing different types of neurons (Sun et al., 2016). However, the induction of specific subtypes of GABAergic neurons is also needed for further understanding of the pathologies. It was reported that ASCL1 and DLX2 overexpression induced various subtypes of GABAergic neurons, such as calretinin $^{+}$, somatostatin ${ }^{+}$, and parvalbumin ${ }^{+}$neurons (Yang et al., 2017). Although parvalbumin ${ }^{+}$neurons have important roles in BP and SCZ (Wang et al., 2011; Marin, 2012), the existing method can induce parvalbumin ${ }^{+}$neurons at only low levels (Sun et al., 2016; Wen, 2017; Yang et al., 2017). Therefore, an efficient method to induce parvalbumin ${ }^{+}$neurons is required for further investigation of the roles of GABAergic neurons in BP and SCZ.

Interestingly, we identified similar phenotypes of decreased $\mathrm{MAP}^{+}$dendrite length and synapse number between BP and SCZ neurons and between glutamatergic and GABAergic neurons. These phenotypes seem to be associated with the common and general pathologies in $\mathrm{BP}$ and $\mathrm{SCZ}$ in terms of neurite extension and synapse formation, similar to the phenotypes observed in the brains of patients. Our microarray analysis suggested that these common phenotypes were associated with cell adhesion. PCDH15 participates in cell-cell adhesion of hair cells at the inner ear by forming tip-link filaments (Jaiganesh et al., 2018), while there are no reports on the precise role of PCDH15 in neural adhesion. Reelin is also involved in cell adhesion. Reelin-dependent signaling pathways regulate neural adhesion (Sekine et al., 2012; Hirota and Nakajima, 2017). Thus, PCDH15 and Reelin are expected to play key roles in neural adhesion to regulate dendrite or synapse formation. Indeed, it is well known that cell adhesion plays important roles in synapse formation and neurite extension (Missler et al., 2012). Previous studies have suggested that cell adhesion molecules are associated with BP and SCZ (O'Dushlaine et al., 2011; Sakurai, 2017). In addition, if such a basic system of neural development is associated with these phenotypes, the phenotypes may be associated with a broader range of psychiatric disorders. Although, based on these observations, cell adhesion is expected to play important roles in the pathologies of $\mathrm{BP}$ and $\mathrm{SCZ}$, it remains unknown whether these phenotypes reflect common pathologies in general patients or are specific to certain genetic backgrounds because of two limitations. First, the number of donors was limited in this study, and further studies are warranted to confirm our findings. Second, the PCDH15 or RELN mRNA levels did not decrease significantly in neurons induced from patient-derived iPSCs according to our QRT-PCR data in contrast to isogenic homozygous $P C D H 15$-deleted or RELN-deleted neurons. A previous report using NEUROG2 overexpression-induced neurons from iPSCs of SCZ patients with heterozygous gene deletion obtained a similar result (Flaherty et al., 2017). Therefore, heterozygous gene deletion does not always indicate the downregulation of gene expression in neurons. Considering that these genes tended to be downregulated in patient-derived DSi-EBs, although these changes were not significant, it is possible that gene expression in patient-derived cells was different from that in the control cells during differentiation.

For further insights into the relationship between CNVs and phenotypes, we established and analyzed isogenic $P C D H 15$-deleted or RELN-deleted iPSCs using genomeediting technology. Although the isogenic lines showed dendritic or synaptic phenotypes partially correlated with those of patient iPSC-derived neurons, these phenotypes of isogenic neurons were weaker. These results suggest that CNVs as well as other factors contribute to these phenotypes. We also confirmed that other clinically important CNVs were not present in the patients, although it is still possible that an unknown genetic background affected the phenotypes or clinical pathologies because BP and SCZ are highly polygenic disorders. If large-scale genome-editing technologies that allow for the rescue of CNVs become available in the future, the contributions of CNVs can be clearly and directly proved. Under these conditions, patient-derived iPSCs may be a better tool than isogenic iPSCs for modeling BP and SCZ.

In addition, we performed functional analysis by measuring spontaneous neural activity to investigate whether the observed structural phenotypes led to functional abnormalities. However, we did not identify any functional differences in spontaneous activity in patient or isogenic neurons. Although our neurons seemed to be immature compared with in vivo neurons, which might make it difficult to detect functional differences, our data suggest that the electrophysiological functions of patient-derived glutamatergic neurons were compensated by the enhancement of sensitivity in their receptors. Although structural abnormalities do not always cause functional defects because a compensatory mechanism might con- 
tribute to functional maintenance, detailed electrophysiological analyses are warranted in future studies. We also showed that our neurons were electrically active to some extent. Therefore, our in vitro model is suitable for further electrophysiological analyses to elucidate the functional significance of CNVs. Also, coculture of both types of our neurons (glutamatergic and GABAergic) or coculture with glial cells, which is expected to promote further functional maturation and neural network formation, may support this approach in the future studies.

For various diseases, potential therapeutic drugs were identified from phenotypic screening using induced tissues from patient-derived iPSCs (Okano and Yamanaka, 2014; Wainger et al., 2014; Hino et al., 2017; Hosoya et al., 2017; Imamura et al., 2017; Kondo et al., 2017; Fujimori et al., 2018; Tabata et al., 2018). Thus, phenotype-recapitulated in vitro model using iPSC technology is available for exploring new therapeutic agents. Our model showing disorder-related phenotypes can be a useful tool for identifying novel drug candidates.

Overall, our approach for the induction of specific neurons from patient-derived iPSCs with disease-related genetic polymorphisms enabled us to analyze pathologyassociated phenotypes. Our in vitro model, which may show general phenotypes of psychiatric disorders, is expected to be applicable for further elucidation of molecular mechanisms or drug discovery.

\section{References}

Ahmed ZM, Riazuddin S, Bernstein SL, Ahmed Z, Khan S, Griffith AJ, Morell RJ, Friedman TB, Riazuddin S, Wilcox ER (2001) Mutations of the protocadherin gene PCDH15 cause Usher syndrome type 1F. Am J Hum Genet 69:25-34.

Alagramam KN, Yuan H, Kuehn MH, Murcia CL, Wayne S, Srisailpathy CR, Lowry RB, Knaus R, Van Laer L, Bernier FP, Schwartz S, Lee C, Morton CC, Mullins RF, Ramesh A, Van Camp G, Hageman GS, Woychik RP, Smith RJ (2001) Mutations in the novel protocadherin PCDH15 cause Usher syndrome type 1F. Hum Mol Genet 10:10.

Arioka $Y$, Shishido E, Kubo H, Kushima I, Yoshimi A, Kimura H, Ishizuka K, Aleksic B, Maeda T, Ishikawa M, Kuzumaki N, Okano H, Mori D, Ozaki N (2018) Single-cell trajectory analysis of human homogenous neurons carrying a rare RELN variant. Transl Psychiatry 8:129.

Bardy C, Van den Hurk M, Eames T, Marchand C, Hernandez RV, Kellogg M, Gorris M, Galet B, Palomares V, Brown J, Bang AG, Mentens J, Bohnke L, Boyer L, Simon S, Gage FH (2015) Neuronal medium that supports basic synaptic functions and activity of human neurons in vitro. Proc Natl Acad Sci U S A 112:10.

Chambers SM, Fasano CA, Papapetrou EP, Tomishima M, Sadelain M, Studer L (2009) Highly efficient neural conversion of human ES and iPS cells by dual inhibition of SMAD signaling. Nat Biotechnol 27:275-280.

Colasante G, Lignani G, Rubio A, Medrihan L, Yekhlef L, Sessa A, Massimino L, Giannelli SG, Sacchetti S, Caiazzo M, Leo D, Alexopoulou D, Dell'Anno MT, Ciabatti E, Orlando M, Studer M, Dahl A, Gainetdinov RR, Taverna S, Benfenati F, Broccoli V (2015) Rapid conversion of fibroblasts into functional forebrain GABAergic interneurons by direct genetic reprogramming. Cell Stem Cell 17: 719-734.

Costain G, Lionel AC, Merico D, Forsythe P, Russell K, Lowther C, Yuen T, Husted J, Stavropoulos DJ, Speevak M, Chow EW, Marshall CR, Scherer SW, Bassett AS (2013) Pathogenic rare copy number variants in community-based schizophrenia suggest a potential role for clinical microarrays. Hum Mol Genet 22:44854501.

Craddock N, Sklar P (2013) Genetics of bipolar disorder. Lancet 381:1654-1662.

Espuny-Camacho I, Michelsen KA, Gall D, Linaro D, Hasche A, Bonnefont J, Bali C, Orduz D, Bilheu A, Herpoel A, Lambert N, Gaspard N, Péron S, Schiffmann SN, Giugliano M, Gaillard A, Vanderhaeghen P (2013) Pyramidal neurons derived from human pluripotent stem cells integrate efficiently into mouse brain circuits in vivo. Neuron 77:440-456.

Flaherty E, Deranieh RM, Artimovich E, Lee IS, Siegel AJ, Levy DL, Nestor MW, Brennand KJ (2017) Patient-derived hiPSC neurons with heterozygous CNTNAP2 deletions display altered neuronal gene expression and network activity. NPJ Schizophr 3:35.

Folsom TD, Fatemi SH (2013) The involvement of Reelin in neurodevelopmental disorders. Neuropharmacology 68:122-135.

Fujimori K, Ishikawa M, Otomo A, Atsuta N, Nakamura R, Akiyama T, Hadano S, Aoki M, Saya H, Sobue G, Okano H (2018) Modeling sporadic ALS in iPSC-derived motor neurons identifies a potential therapeutic agent. Nat Med 24:1579-1589.

Gao R, Penzes P (2015) Common mechanisms of excitatory and inhibitory imbalance in schizophrenia and autism spectrum disorders. Curr Mol Med 15:22.

Georgieva L, Rees E, Moran JL, Chambert KD, Milanova V, Craddock N, Purcell S, Sklar P, McCarroll S, Holmans P, O'Donovan MC, Owen MJ, Kirov G (2014) De novo CNVs in bipolar affective disorder and schizophrenia. Hum Mol Genet 23:6677-6683.

Glantz LA, Lewis DA (2000) Decreased dendritic spine density on prefrontal cortical pyramidal neurons in schizophrenia. Arch Gen Psychiatry 57:65-73.

Grande I, Berk M, Birmaher B, Vieta E (2016) Bipolar disorder. Lancet 387:1561-1572.

Green EK, Rees E, Walters JT, Smith KG, Forty L, Grozeva D, Moran JL, Sklar P, Ripke S, Chambert KD, Genovese G, McCarroll SA, Jones I, Jones L, Owen MJ, O'Donovan MC, Craddock N, Kirov G (2016) Copy number variation in bipolar disorder. Mol Psychiatry 21:89-93.

Han SS, Williams LA, Eggan KC (2011) Constructing and deconstructing stem cell models of neurological disease. Neuron 70 : 626-644

Hino K, Horigome K, Nishio M, Komura S, Nagata S, Zhao C, Jin Y, Kawakami K, Yamada Y, Ohta A, Toguchida J, Ikeya M (2017) Activin-A enhances mTOR signaling to promote aberrant chondrogenesis in fibrodysplasia ossificans progressiva. J Clin Invest 127: 3339-3352.

Hirota Y, Nakajima K (2017) Control of neuronal migration and aggregation by reelin signaling in the developing cerebral cortex. Front Cell Dev Biol 5:40.

Hosoya M, Fujioka M, Sone T, Okamoto S, Akamatsu W, Ukai H, Ueda HR, Ogawa K, Matsunaga T, Okano H (2017) Cochlear cell modeling using disease-specific iPSCs unveils a degenerative phenotype and suggests treatments for congenital progressive hearing loss. Cell Rep 18:68-81.

Imaizumi K, Sone T, Ibata K, Fujimori K, Yuzaki M, Akamatsu W, Okano H (2015) Controlling the regional identity of hpsc-derived neurons to uncover neuronal subtype specificity of neurological disease phenotypes. Stem Cell Reports 5:1010-1022.

Imaizumi Y, Okada Y, Akamatsu W, Koike M, Kuzumaki N, Hayakawa $H$, Nihira $T$, Kobayashi $T$, Ohyama M, Sato S, Takanashi M, Funayama M, Hirayama A, Soga T, Hishiki T, Suematsu M, Yagi T, Ito D, Kosakai A, Hayashi K, et al. (2012) Mitochondrial dysfunction associated with increased oxidative stress and $\alpha$-synuclein accumulation in PARK2 iPSC-derived neurons and postmortem brain tissue. Mol Brain 5:35.

Imamura K, Izumi Y, Watanabe A, Tsukita K, Woltjen K, Yamamoto T, Hotta A, Kondo T, Kitaoka S, Ohta A, Tanaka A, Watanabe D, Morita M, Takuma H, Tamaoka A, Kunath T, Wray S, Furuya H, Era T, Makioka K, et al. (2017) The Src/c-Abl pathway is a potential therapeutic target in amyotrophic lateral sclerosis. Sci Transl Med 9:eaaf3962. 
Ishii K, Kubo KI, Nakajima K (2016) Reelin and neuropsychiatric disorders. Front Cell Neurosci 10:229.

Isoda M, Kohyama J, Iwanami A, Sanosaka T, Sugai K, Yamaguchi R, Matsumoto T, Nakamura M, Okano H (2016) Robust production of human neural cells by establishing neuroepithelial-like stem cells from peripheral blood mononuclear cell-derived feeder-free iPSCs under xeno-free conditions. Neurosci Res 110:18-28.

Jaiganesh A, Narui Y, Araya-Secchi R, Sotomayor M (2018) Beyond cell-cell adhesion: sensational cadherins for hearing and balance. Cold Spring Harb Perspect Biol 10:a029280.

Kim S-Y, Yasuda S, Tanaka H, Yamagata K, Kim H (2011) Nonclustered protocadherin. Cell Adh Migr 5:97-105.

Kiryushko D, Berezin V, Bock E (2004) Regulators of neurite outgrowth: role of cell adhesion molecules. Ann N Y Acad Sci 1014: 140-154.

Kondo T, Imamura K, Funayama M, Tsukita K, Miyake M, Ohta A, Woltjen K, Nakagawa M, Asada T, Arai T, Kawakatsu S, Izumi Y, Kaji R, Iwata N, Inoue H (2017) iPSC-based compound screening and in vitro trials identify a synergistic anti-amyloid $\beta$ combination for Alzheimer's disease. Cell Rep 21:2304-2312.

Konopaske GT, Lange N, Coyle JT, Benes FM (2014) Prefrontal cortical dendritic spine pathology in schizophrenia and bipolar disorder. JAMA Psychiatry 71:1323-1331.

Kushima I, Aleksic B, Nakatochi M, Shimamura T, Shiino T, Yoshimi A, Kimura H, Takasaki Y, Wang C, Xing J, Ishizuka K, Oya-Ito T, Nakamura Y, Arioka Y, Maeda T, Yamamoto M, Yoshida M, Noma H, Hamada S, Morikawa M, et al. (2017) High-resolution copy number variation analysis of schizophrenia in Japan. Mol Psychiatry 22:430-440.

Lee GH, D'Arcangelo G (2016) New insights into reelin-mediated signaling pathways. Front Cell Neurosci 10:122.

Lee Y, Zhang Y, Kim S, Han K (2018) Excitatory and inhibitory synaptic dysfunction in mania: an emerging hypothesis from animal model studies. Exp Mol Med 50:12.

Lo MT, Hinds DA, Tung JY, Franz C, Fan CC, Wang Y, Smeland OB, Schork A, Holland D, Kauppi K, Sanyal N, Escott-Price V, Smith DJ, O'Donovan M, Stefansson H, Bjornsdottir G, Thorgeirsson TE, Stefansson K, McEvoy LK, Dale AM, et al. (2017) Genome-wide analyses for personality traits identify six genomic loci and show correlations with psychiatric disorders. Nat Genet 49:152-156.

Madison JM, Zhou F, Nigam A, Hussain A, Barker DD, Nehme R, van der Ven K, Hsu J, Wolf P, Fleishman M, O'Dushlaine C, Rose S, Chambert K, Lau FH, Ahfeldt T, Rueckert EH, Sheridan SD, Fass DM, Nemesh J, Mullen TE, et al. (2015) Characterization of bipolar disorder patient-specific induced pluripotent stem cells from a family reveals neurodevelopmental and mRNA expression abnormalities. Mol Psychiatry 20:703-717.

Maggioni E, Crespo-Facorro B, Nenadic I, Benedetti F, Gaser C, Sauer H, Roiz-Santiañez R, Poletti S, Marinelli V, Bellani M, Perlini C, Ruggeri M, Altamura AC, Diwadkar VA, Brambilla P (2017) Common and distinct structural features of schizophrenia and bipolar disorder: the European Network on Psychosis, Affective disorders and Cognitive Trajectory (ENPACT) study. PLoS One 12:e0188000.

Marin O (2012) Interneuron dysfunction in psychiatric disorders. Nat Rev Neurosci 13:107-120.

Matsumoto T, Fujimori K, Andoh-Noda T, Ando T, Kuzumaki N, Toyoshima M, Tada H, Imaizumi K, Ishikawa M, Yamaguchi R, Isoda M, Zhou Z, Sato S, Kobayashi T, Ohtaka M, Nishimura K, Kurosawa H, Yoshikawa T, Takahashi T, Nakanishi M, et al. (2016) Functional neurons generated from $\mathrm{T}$ cell-derived induced pluripotent stem cells for neurological disease modeling. Stem Cell Reports 6:422-435.

Matsushita M, Nakatake Y, Arai I, Ibata K, Kohda K, Goparaju SK, Murakami M, Sakota M, Chikazawa-Nohtomi N, Ko SBH, Kanai T, Yuzaki M, Ko MSH (2017) Neural differentiation of human embryonic stem cells induced by the transgene-mediated overexpression of single transcription factors. Biochem Biophys Res Commun 490:296-301.
McGrath J, Saha S, Chant D, Welham J (2008) Schizophrenia: a concise overview of incidence, prevalence, and mortality. Epidemiol Rev 30:67-76.

Millan MJ, Andrieux A, Bartzokis G, Cadenhead K, Dazzan P, FusarPoli P, Gallinat J, Giedd J, Grayson DR, Heinrichs M, Kahn R, Krebs MO, Leboyer M, Lewis D, Marin O, Marin P, MeyerLindenberg A, McGorry P, McGuire P, Owen MJ, et al. (2016) Altering the course of schizophrenia: progress and perspectives. Nat Rev Drug Discov 15:485-515.

Missler M, Südhof TC, Biederer T (2012) Synaptic cell adhesion. Cold Spring Harb Perspect Biol 4:a005694.

Nakagawa M, Taniguchi Y, Senda S, Takizawa N, Ichisaka T, Asano K, Morizane A, Doi D, Takahashi J, Nishizawa M, Yoshida Y, Toyoda T, Osafune K, Sekiguchi K, Yamanaka S (2014) A novel efficient feeder-free culture system for the derivation of human induced pluripotent stem cells. Sci Rep 4:3594.

Nehme R, Zuccaro E, Ghosh SD, Li C, Sherwood JL, Pietilainen O, Barrett LE, Limone F, Worringer KA, Kommineni S, Zang Y, Cacchiarelli D, Meissner A, Adolfsson R, Haggarty S, Madison J, Muller M, Arlotta P, Fu Z, Feng G, et al. (2018) Combining NGN2 programming with developmental patterning generates human excitatory neurons with NMDAR-mediated synaptic transmission. Cell Rep 23:2509-2523.

Noor A, Lionel AC, Cohen-Woods S, Moghimi N, Rucker J, Fennell A, Thiruvahindrapuram B, Kaufman L, Degagne B, Wei J, Parikh SV, Muglia P, Forte J, Scherer SW, Kennedy JL, Xu W, McGuffin P, Farmer A, Strauss J, Vincent JB (2014) Copy number variant study of bipolar disorder in Canadian and UK populations implicates synaptic genes. Am J Med Genet B Neuropsychiatr Genet 165B: 303-313.

O'Dushlaine C, Kenny E, Heron E, Donohoe G, Gill M, Morris D, Corvin A (2011) Molecular pathways involved in neuronal cell adhesion and membrane scaffolding contribute to schizophrenia and bipolar disorder susceptibility. Mol Psychiatry 16:286-292.

Okada Y, Shimazaki T, Sobue G, Okano H (2004) Retinoic-acidconcentration-dependent acquisition of neural cell identity during in vitro differentiation of mouse embryonic stem cells. Dev Biol 275:124-142.

Okano H, Yamanaka S (2014) iPS cell technologies: significance and applications to CNS regeneration and disease. Mol Brain 7:22.

Okita K, Matsumura Y, Sato Y, Okada A, Morizane A, Okamoto S, Hong H, Nakagawa M, Tanabe K, Tezuka K, Shibata T, Kunisada T, Takahashi M, Takahashi J, Saji H, Yamanaka S (2011) A more efficient method to generate integration-free human iPS cells. Nat Methods 8:409-412.

Okita K, Yamakawa T, Matsumura Y, Sato Y, Amano N, Watanabe A, Goshima N, Yamanaka S (2013) An efficient nonviral method to generate integration-free human-induced pluripotent stem cells from cord blood and peripheral blood cells. Stem Cells 31:458466.

O'Shea KS, Mclnnis MG (2016) Neurodevelopmental origins of bipolar disorder: iPSC models. Mol Cell Neurosci 73:63-83.

Owen MJ, O'Donovan MC (2017) Schizophrenia and the neurodevelopmental continuum: evidence from genomics. World Psychiatry 16:227-235.

Prytkova I, Brennand KJ (2017) Prospects for modeling abnormal neuronal function in schizophrenia using human induced pluripotent stem cells. Front Cell Neurosci 11:360.

Rutkowski TP, Schroeder JP, Gafford GM, Warren ST, Weinshenker D, Caspary T, Mulle JG (2017) Unraveling the genetic architecture of copy number variants associated with schizophrenia and other neuropsychiatric disorders. J Neurosci Res 95:1144-1160.

Sakurai T (2017) The role of cell adhesion molecules in brain wiring and neuropsychiatric disorders. Mol Cell Neurosci 81:4-11.

Sekine K, Kawauchi T, Kubo K, Honda T, Herz J, Hattori M, Kinashi T, Nakajima K (2012) Reelin controls neuronal positioning by promoting cell-matrix adhesion via inside-out activation of integrin $\alpha 5 \beta 1$. Neuron 76:353-369.

Shimazaki T, Shingo T, Weiss S (2001) The ciliary neurotrophic factor/leukemia inhibitory factor/gp130 receptor complex operates 
in the maintenance of mammalian forebrain neural stem cells. $J$ Neurosci 21:7642-7653.

Sobue A, Kushima I, Nagai T, Shan W, Kohno T, Aleksic B, Aoyama Y, Mori D, Arioka Y, Kawano N, Yamamoto M, Hattori M, Nabeshima T, Yamada K, Ozaki N (2018) Genetic and animal model analyses reveal the pathogenic role of a novel deletion of RELN in schizophrenia. Sci Rep 8:13046.

Sun AX, Yuan Q, Tan S, Xiao Y, Wang D, Khoo AT, Sani L, Tran HD, Kim P, Chiew YS, Lee KJ, Yen YC, Ng HH, Lim B, Je HS (2016) Direct induction and functional maturation of forebrain GABAergic neurons from human pluripotent stem cells. Cell Rep 16:19421953.

Tabata Y, Imaizumi Y, Sugawara M, Ando-Noda T, Banno S, Chai M, Sone T, Yamazaki K, Ito M, Tsukahara K, Saya H, Hattori N, Kohyama J, Okano H (2018) T-type calcium channels determine the vulnerability of dopaminergic neurons to mitochondrial stress in familial Parkinson's disease. Stem Cell Reports 11:1171-1184.

Takahashi K, Tanabe K, Ohnuki M, Narita M, Ichisaka T, Tomoda K, Yamanaka S (2007) Induction of pluripotent stem cells from adult human fibroblasts by defined factors. Cell 131:861-872.

Tobe BTD, Crain AM, Winquist AM, Calabrese B, Snyder EY (2017) Probing the lithium-response pathway in hiPSCs implicates the phosphoregulatory set-point for a cytoskeletal modulator in bipolar pathogenesis. Proc Natl Acad Sci U S A 114:10.

Toyoshima M, Akamatsu W, Okada Y, Ohnishi T, Balan S, Hisano Y, Iwayama $\mathrm{Y}$, Toyota $\mathrm{T}$, Matsumoto $\mathrm{T}$, Itasaka $\mathrm{N}$, Sugiyama $\mathrm{S}$, Tanaka M, Yano M, Dean B, Okano H, Yoshikawa T (2016) Analysis of induced pluripotent stem cells carrying 22q11.2 deletion. Transl Psychiatry 6:e934.

Wainger BJ, Kiskinis E, Mellin C, Wiskow O, Han SS, Sandoe J, Perez NP, Williams LA, Lee S, Boulting G, Berry JD, Brown RH Jr, Cudkowicz ME, Bean BP, Eggan K, Woolf CJ (2014) Intrinsic membrane hyperexcitability of amyotrophic lateral sclerosis patient-derived motor neurons. Cell Rep 7:1-11.

Wang AY, Lohmann KM, Yang CK, Zimmerman El, Pantazopoulos H, Herring N, Berretta S, Heckers S, Konradi C (2011) Bipolar disorder type 1 and schizophrenia are accompanied by decreased density of parvalbumin- and somatostatin-positive interneurons in the parahippocampal region. Acta Neuropathol 122:615-626.

Watmuff B, Berkovitch SS, Huang JH, laconelli J, Toffel S, Karmacharya R (2016) Disease signatures for schizophrenia and bipolar disorder using patient-derived induced pluripotent stem cells. Mol Cell Neurosci 73:96-103.

Wen Z (2017) Modeling neurodevelopmental and psychiatric diseases with human iPSCs. J Neurosci Res 95:1097-1109.

Yang N, Chanda S, Marro S, Ng YH, Janas JA, Haag D, Ang CE, Tang Y, Flores Q, Mall M, Wapinski O, Li M, Ahlenius H, Rubenstein JL, Chang HY, Buylla AA, Südhof TC, Wernig M (2017) Generation of pure GABAergic neurons by transcription factor programming. Nat Methods 14:621-628.

Zhang Y, Pak C, Han Y, Ahlenius H, Zhang Z, Chanda S, Marro S, Patzke C, Acuna C, Covy J, Xu W, Yang N, Danko T, Chen L, Wernig M, Südhof TC (2013) Rapid single-step induction of functional neurons from human pluripotent stem cells. Neuron 78:785798. 